\title{
Testing for aggression and nestmate recognition in the eastern subterranean termite (Reticulitermes flavipes)
}

Victoria K. Simkovic, The University of Western Ontario

Supervisor: Dr. Jeremy McNeil, The University of Western Ontario

Joint Supervisor: Dr. Graham Thompson, The University of Western Ontario

A thesis submitted in partial fulfillment of the requirements for the Master of Science degree in Biology

(C) Victoria K. Simkovic 2016

Follow this and additional works at: https://ir.lib.uwo.ca/etd

\section{Recommended Citation}

Simkovic, Victoria K., "Testing for aggression and nestmate recognition in the eastern subterranean termite (Reticulitermes flavipes)" (2016). Electronic Thesis and Dissertation Repository. 3789.

https://ir.lib.uwo.ca/etd/3789

This Dissertation/Thesis is brought to you for free and open access by Scholarship@Western. It has been accepted for inclusion in Electronic Thesis and Dissertation Repository by an authorized administrator of Scholarship@Western. For more information, please contact wlswadmin@uwo.ca. 


\section{Abstract}

Although social insects generally live within defined colony boundaries that are defended against intruders, under certain conditions populations may form expansive supercolonies with no evidence of overt aggression. Supercolony formation may be the result of an introduction event, where colonies lack aggression and possibly nestmate recognition, or may be related to the amount of resource abundance. In the case of the eastern subterranean termite (Reticulitermes flavipes) there are conflicting reports in the literature with regards to whether there is intraspecific aggression between colonies, some studies suggesting that aggressive behavior is displayed towards non-nestmates while others have concluded that it is a non-aggressive species. $R$. flavipes was first reported over 80 years ago in Toronto, where populations exhibit characteristics suggestive of supercolonies. However, more recently, genetically different populations have been found near Point Pelee where they form discrete colonies. The purpose of this thesis was to investigate the level of aggression and nestmate recognition within and between geographically different populations. If aggressive behavior exists then the level of intercolony aggression and mortality would be expected to increase with increasing geographic distance between colonies. Overall, no overt aggression was observed in any nestmate or non-nestmate pairings in 5-minute Petri dish trials (varying both caste and density). However, in two and seven-day resource design pairings the incidence of mortality was high in the nonnestmate assays when colonies from Toronto and Pelee Island were paired. Furthermore, in these assays nestmates readily intermixed while non-nestmates did not. These results indicate that $R$. flavipes recognizes kin from non-kin, regardless of their geographic origin or whether they form individual or supercolonies. Although they probably reduce aggressive interaction through the avoidance of non-kin, the high mortality observed in Toronto-Pelee pairings suggest that they express aggression under certain ecological conditions, possibly when foraging galleries intersect. It is also clear from this study that the design of the bioassay used can significantly affect the outcome observed, so care should be taken to test under conditions that are most reflective of field conditions. 
Keywords: Reticulitermes flavipes, termite, aggression, nestmate recognition, supercolony 


\section{Acknowledgments}

I would like to thank Dr. Jeremy McNeil for his incredible support, patience and commitment towards helping me succeed in and complete my Masters of Science. I am truly thankful that he agreed to be my co-supervisor. Even with supervising many other graduate students, he still took me under his wing and always made time to answer my

questions. I greatly valued his advice, knowledge and expertise. He gave me the freedom to explore ideas and to grow as a scientist.

I would like to thank my committee members Dr. Brent Sinclair and Dr. Nusha Keyghobadi for their very useful comments and critical feedback throughout the project. I would also like to thank Dr. Graham Thompson for giving me the opportunity to go to graduate school and for his assistance in financing this project. Many other individuals provided tremendous help during this project. Jonathan Jacobs helped assemble my resource design experiments and provided useful suggestions. Dr. Ben Rubin provided invaluable statistical advice and was incredibly patient throughout the writing of my thesis. Various agencies assisted me in gaining knowledge of field colony locations, completing collection permits and accessing field sites, including Aetna Pest Control (Liz Murphy), homeowner Donna Branniff, Nature Conservancy of Canada (Mhairi McFarlane, Jill Crosthwaite), Point Pelee National Park (Tammy Dobbie), and the Ministry of Natural Resources.

I would like to thank other faculty that provided feedback and advice, including Dr. Marc-André Lachance, Dr. Nina Zitani and Dr. Greg Thorn. I am also thankful for all of the kind and supportive people I met along the way at Western University, both faculty and graduate students. I am appreciative of the Nature Conservancy of Canada for allowing me to stay at the Ivey Research Station on Pelee Island while I completed my field collection.

My husband James MacKay has been a tremendous source of encouragement, love and support throughout this project, which I am grateful for. I am also thankful for all the individuals in my past that inspired me to fall in love with animal behavior, return to graduate school and pursue my passion for nature - in particular Dr. Darryl Gwynne. I 
would also like to acknowledge my parents, for without them I wouldn't be the person I am today.

My last thanks go to our pet rats, Ezri and Athena, whose antics provided great comedic relief while I wrote my thesis. This included running over a useful 'hot key' by mistake on my keyboard, allowing me to quickly speed up or slow down video on VLC media player as I took measurements. 


\section{Table of Contents}

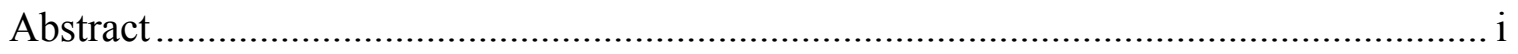

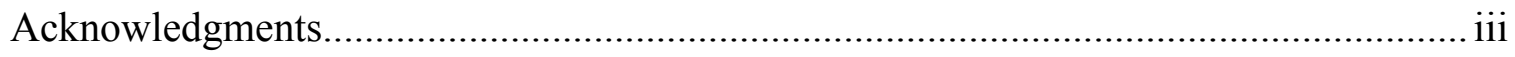

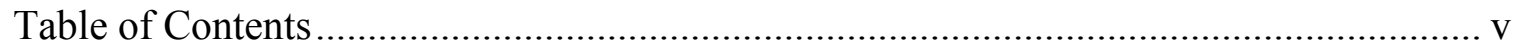

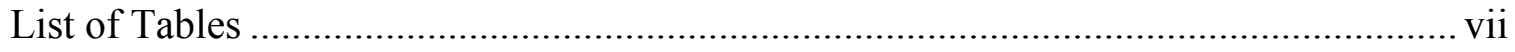

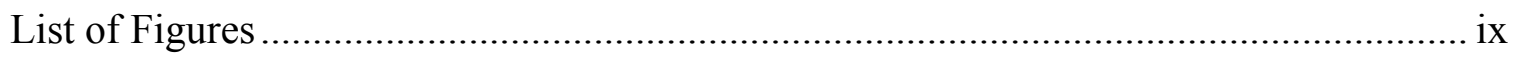

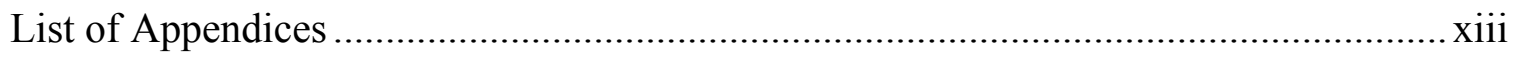

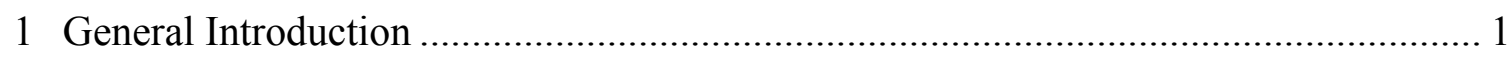

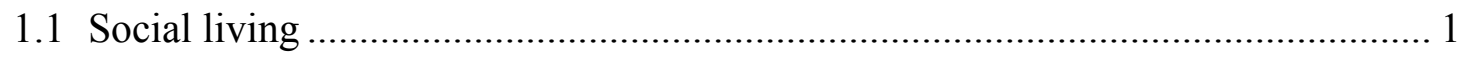

1.2 Social insects defend nest territory ........................................................ 1

1.3 Kin-based defenses can be absent ........................................................... 2

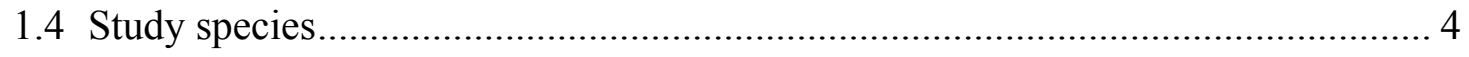

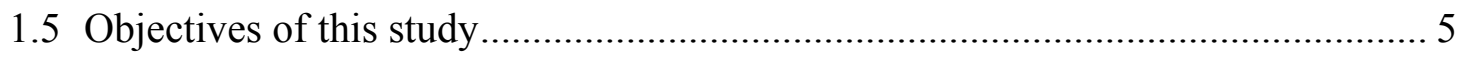

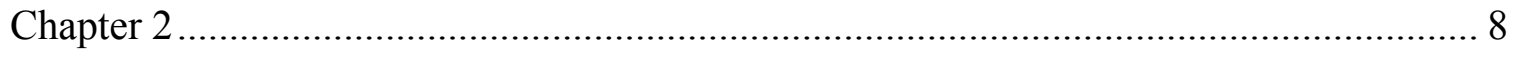

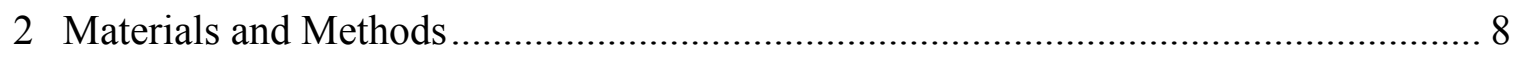

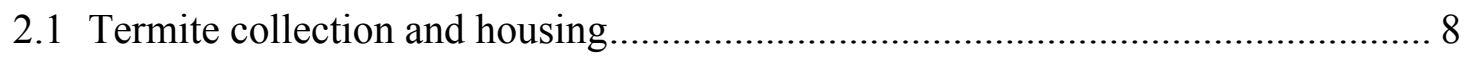

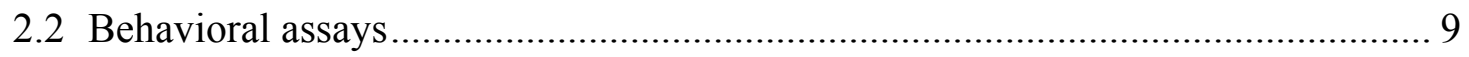

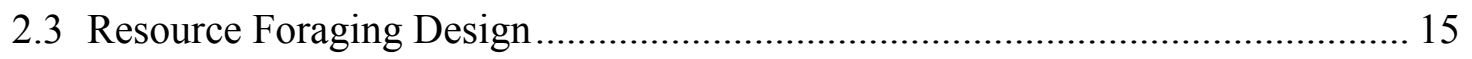

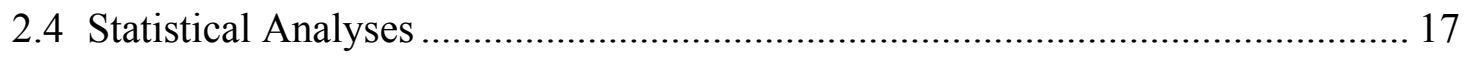

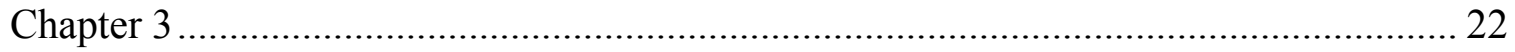

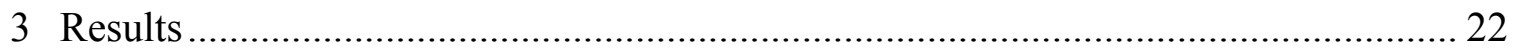

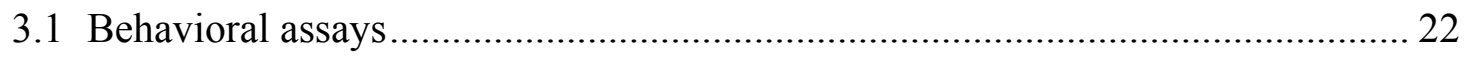

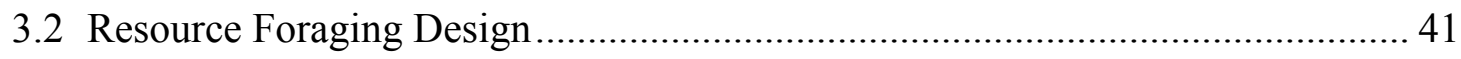

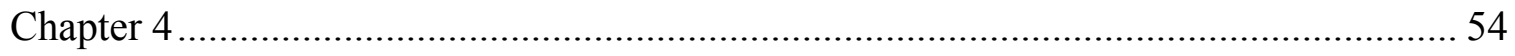

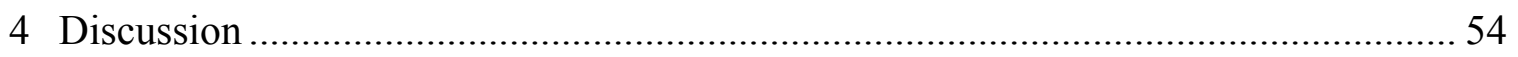




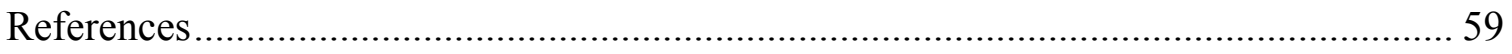

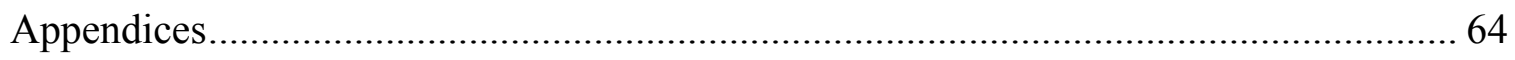

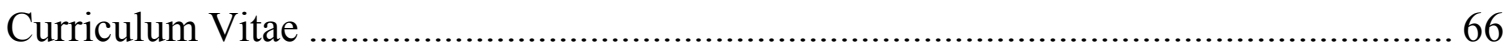




\section{List of Tables}

Table 2.1. Classification of behavioral responses and relative intensity of aggression scoring scale used in behavioral assays of the Eastern subterranean termite $R$. flavipes to obtain a 5-minute mean aggression score.

Table 2.2. Number of replicates for geographic distance pairings. One-on-one residentintruder pairings of different castes $(\mathrm{ww}=$ worker-worker, ws $=$ worker-soldier, $\mathrm{ss}=$ soldier-soldier $)$ and colony source $(\mathrm{NM}=$ nestmate, $\mathrm{NNM}=$ non-nestmate $)$. 14

Table 3.1. Percentage of aggressive responses (\% aggr. responses), mean aggression score (MAS) and total \# of interactions for one-on-one pairings with Toronto (TO), Pelee Island (PI) or Point Pelee (PP) pairings $(\mathrm{n}=10$ per pairing). $\mathrm{RI}=$ Resident response to intruder, IR = Intruder response to resident, $\mathrm{ww}=$ worker-worker, $\mathrm{ws}=$ worker-soldier, ss $=$ soldier-soldier.

Table 3.2. Summary of one-way independent ANOVA for mean aggression score of the resident termite in response to an intruder and intruder termite in response to a resident, comparing differences between situations where individuals were from the same (T-T, PP) or different (T-P, P-T) colony. Interactions were between worker-worker (ww), worker-soldier (ws) or soldier-soldier (ss) pairings

Table 3.3. Summary of one-way independent ANOVA for mean antennation time (s) of the resident termite in response to an intruder and intruder termite in response to a resident in one-on-one pairings, comparing differences between situations where individuals were from the same (TO-TO or PI-PI) colony or different (TO-PI or PI-TO) colonies. Interactions were between worker-worker (ww), worker-soldier (ws) or soldiersoldier (ss) pairings. 30

Table 3.4. Range of the number of antennations per replicate for the resident's response to intruder and intruder's response to resident of the same (TO-TO or PI-PI) colony or different (TO-PI, PI-TO) colonies, one-on-one interactions. $\mathrm{n}=10$ per caste pairing, $\mathrm{ww}$ $=$ worker-worker, ws $=$ worker-soldier, $\mathrm{ss}=$ soldier-soldier. 
Table 3.5. Percentage of aggressive responses and mean aggression score (MAS) over summed interactions for all five-on-one and five-on-five Toronto - Pelee pairings.

RI (resident-intruder), IR (intruder-resident), RR (resident-resident) and II (intruderintruder) are all tabulated from the same number of replicates (therefore total \# interactions is the same). $\mathrm{n}=10$ per caste pairing, $\mathrm{ww}=$ worker-worker, ws $=$ workersoldier, $\mathrm{ss}=$ soldier-soldier, $\mathrm{NNM}=$ non-nestmate, $\mathrm{NM}=$ nestmate.

Table 3.6. Summary of one-way independent ANOVA for differences in mean antennation time (s) between nestmates (resident-resident, intruder-intruder) and nonnestmates (resident-intruder, intruder-resident) for all five-on-one and five-on-five Toronto - Pelee pairings. $\mathrm{n}=10$ per caste pairing (ww (worker-worker), ws (workersoldier) and ss (soldier-soldier)). Asterisks denote statistical significance $(P<0.05) \ldots . .35$

Table 3.7. Effects of density on antennation time. Summary of one-way independent ANOVA for mean antennation time (s) of the resident response to an intruder and intruder response to resident comparing one-on-one, five-on-one and five-on-five density non-nestmate pairings. Scores compared for ww (worker-worker), ws (worker-soldier), ss (soldier-soldier) pairings. Asterisk denotes statistical significance. $\mathrm{n}=10$ per density pairing. 38

Table 3.8. Summary of quasi binomial logistic regression comparing whether surviving $R$. flavipes workers moved from or stayed in their home container after seven days when paired with nestmates (TO-TO, PI-PI) or non-nestmates (TO-PI). $\mathrm{n}=12$ (4 per pairing). Constant value $=$ TO-TO pairing, dispersion parameter $=25.3$.

Table 3.9. Two-day resource design, Toronto - Toronto (TO - TO), Pele Island - Pelee Island (nestmate) pairings, Toronto - Pelee Island (non-nestmate) pairings, replicates \#115. Total number of survivors in each compartment (left, middle, right) and total survivorship (15 stained, 15 unstained, /30).

Table 3.10. One way ANOVA for differences in survivorship between stained versus unstained individuals, in Pelee Island - Pelee Island (PIPI), Toronto-Toronto (TO-TO) and Toronto - Pelee Island (TO-PI) pairings in seven-day and two-day resource design assays. 
Table 3.11. Number of dead individuals found in the left, middle, right compartments or glass tubes for TO-TO, PI-PI and TO-PI pairings in the seven-day resource foraging design.

\section{List of Figures}

Figure 2.1. Cardboard roll trap collection method. A single face, two-ply corrugated cardboard roll (top left) was used as an attractant to termites, and buried one inch below the soil surface with a plywood lid (top right, bottom left). Traps were buried in in three main sites: Toronto (top right), Pelee Island (bottom left), Point Pelee National Park (bottom right).

Figure 2.2. Petri dish $(3.5 \mathrm{~cm})$ behavioral assay set-up for a) five-on-one and b) five-onfive colony pairings. In five-on-one pairings, antennation and aggression scores were calculated between Resident (Res) - Intruder (Int) (non-nestmate pairings) and Resident - Resident (nestmate). In five-on-five pairings interactions between Intruder - Intruder were also included.

Figure 2.3. Seven-day resource foraging design set-up. Left and right Tupperware containers were filled with moist sand and connected directly or to the middle resource by glass tubing. 500 workers, either stained or unstained were added to the left or right container. The middle resource contained two cardboard rolls and moist wood shavings as a food resource

Figure 2.4. Nile Blue A cell stain. Individual workers were divided into two groups and fed stained (top left) or unstained filter paper (top right). After 2-3 days stained individuals would turn a blue color (bottom photo).

Figure 2.5. Two-day resource foragingdesign set-up, using a $9.5 \mathrm{~cm}$ Petri dish divided into three compartments. 15 stained and 15 unstained individuals were added to the left and right compartments containing moist sand, connected to a middle food resource containing moist filter paper. 
Figure 3.1. Mean antennation time ( $\pm \mathrm{SE}$ ) for one-on-one worker-worker pairings between nestmates $(\mathrm{TO}-\mathrm{TO})$ and non-nestmates $\left(\mathrm{TO}_{\mathrm{A}}-\mathrm{TO}_{\mathrm{B}}, \mathrm{TO}-\mathrm{PP}, \mathrm{TO}-\mathrm{PI}\right)$. Fig. 3.1 a represents antennation time of resident in response to intruder, Fig. 3.1b antennation time of intruder in response to resident. $n=40,10$ replicates per pairing 26

Figure 3.2. Mean antennation time for one-on-one worker-worker pairings comparing a) the Pelee Island resident response to intruder and b) Pelee Island intruder response to resident at various geographic distances. $n=30,10$ replicates per geographic pairing. .. 27

Figure 3.3. Mean antennation time ( $\pm \mathrm{SE}$ ) for one-on-one worker-soldier pairings between nestmates (TO - TO, PI - PI) and non-nestmates (TO - PI, PI - TO). Fig. 3.3a represents antennation time of resident in response to intruder, Fig. 3.3b antennation time of intruder in response to resident. $n=40,10$ replicates per pairing. 28

Figure 3.4. Mean antennation time ( $\mathrm{s} \pm \mathrm{SE}$ ) for 1-on-1 soldier-soldier pairings between nestmates (TO - TO, PI - PI) and non-nestmates (TO - PI, PI - TO). Fig. 3.4a represents antennation time of resident in response to intruder, Fig. 3.4b antennation time of intruder in response to resident. $n=40,10$ replicates per pairing 29

Figure 3.5. Mean antennation time ( \pm SE) for a) worker - worker (ww), b) worker soldier (ws) and c) soldier-soldier (ss) five-on-one pairings. Resident-intruder (R - I) indicate mean scores for non-nestmate pairings (NNM, Toronto - Pelee Island), Resident-Resident (R-R) mean scores for nestmate pairings (NM, Toronto-Toronto or Pelee-Pelee). Letters in b) and c) denote statistical significance between groups ( $p<$ $0.01) . \mathrm{n}=10$ replicates per caste pairing (ww, ws, ss). 36

Figure 3.6. Mean antennation time ( $\pm \mathrm{SE}$ ) for a) worker - worker (ww), b) worker soldier (ws) and c) soldier-soldier (ss) five-on-five pairings. Resident-intruder (R - I) and intruder-resident $(\mathrm{I}-\mathrm{R})$ graphs indicate mean scores for non-nestmate pairings (NNM, TO - PI), Resident-Resident (R-R) and Intruder-Intruder (I-I) indicate mean scores for nestmate pairings (NM, TO-TO or PI-PI). Letters in b) denote statistical significance between groups $(\mathrm{p}<0.05) . \mathrm{n}=10$ replicates per caste pairing (ww, ws, $s)$. 
Figure 3.7. Mean antennation time (s) for one-on-one, five-on-one and five-on-five group pairings, intruder response to resident. Fig. 3.7 a) ww (worker-worker), b) ws (workersoldier) and c) ss (soldier-soldier)

Figure 3.8. Mean antennation time (s) for one-on-one, five-on-one and five-on-five group pairings, resident response to intruder. Fig. 3.8 a) ww (worker-worker), b) ws (workersoldier) and c) ss (soldier-soldier). Different letters denote statistical significance......... 40

Figure 3.9. Seven-day resource design, Pelee Island - Pelee Island (nestmate) pairings, replicates \#1-4. Pie charts indicate the number of stained (gray) and unstained (white) survivors in left or right compartments, and total \# of survivors in middle compartment. Shade of background square indicates which side stained (gray) or unstained (white) individuals were placed at the start of the experiment....

Figure 3.10. Seven-day resource design, Toronto - Toronto (TO-TO) (nestmate) pairings, replicates \#1-4. Pie charts indicate the number of stained (gray) and unstained (white) survivors in left or right compartments, and total \# of survivors in middle compartment. Shade of background square indicates which side stained (gray) or unstained (white) was placed at the start of the experiment.... .44

Figure 3.11. Seven-day resource design, Toronto - Pelee Island (non-nestmate) pairings, replicates \#1-4. Pie charts indicate the number of stained (gray) and unstained (white) survivors in left or right compartments, and total \# of survivors in middle compartment. Shade of background square indicates which side stained (gray) or unstained (white) was placed at the start of the experiment.

Figure 3.12. Seven-day resource design, Toronto locale A - Toronto locale B $\left(\mathrm{TO}_{\mathrm{A}}-\right.$ $\mathrm{TO}_{\mathrm{B}}$ ) (non-nestmate) pairings, replicates \#1-2 (top) and Point Pelee - Pelee Island (PP PI) (non-nestmate) pairings, replicates \#1-2 (bottom). Pie charts indicate proportion and $\%$ of stained (gray) and unstained (white) survivors in left or right compartments. Shade of background square indicates which side stained (gray) or unstained (white) was placed at the start of the experiment. 46 
Figure 3.13. Mean total survivorship ( $\pm \mathrm{SE}$ ) in a) seven-day resource design, and b) twoday resource design trials with combined survivorship of stained and unstained workers.

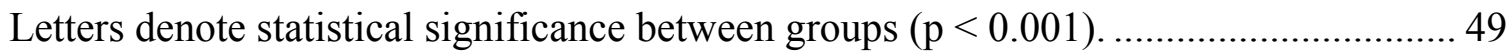

Figure 3.14. Mean survivorship in a) seven-day and b) two-day resource design assays

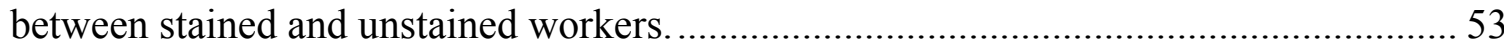




\section{List of Appendices}

Appendix A: Mean aggression score for 1-on-1 a) worker-worker, b) worker-soldier, and

c) soldier-soldier pairings between nestmates (TO - TO, PI - PI) and non-nestmates

(TO - PI, PI - TO).

Appendix B: Mean aggression score for 1-on-1 soldier-soldier non-agitated nestmate pairings (TO TO = Toronto-Toronto), agitated nestmate pairings (TO TO Ag = TorontoToronto), non-agitated non-nestmate pairings (TO PI = Toronto-Pelee Island), agitated non-nestmate pairings $(\mathrm{TO} \mathrm{PI}=$ Toronto-Pelee Island $)$. Asterisk denotes statistical significance using Tukey's poc hoc test $(\mathrm{p}<0.05)$. 


\section{General Introduction}

\subsection{Social living}

In the natural world, social living has evolved as an important life history strategy for a diversity of animal species, conferring numerous benefits to individuals (Oster and Wilson, 1978; Rubenstein 1978; Crespi, 1994). Eusocial societies represent the most structured form of social living and within the Insecta they are found in the Orders Hymenoptera (ants, bees, wasps), Isoptera (termites) and Homoptera (aphids) (Queller and Strassmann, 1998; Bourke 2011). Eusocial insects characteristically live within closely related family units or kin-groups consisting of a reproductive pair with their sterile offspring (Wilson, 1971). Through division of labor, sterile offspring or castes collectively perform colony tasks such as brood care, foraging and nest defense (Wilson, 1971; Oster and Wilson, 1978; Thorne, 1997; Queller and Strassmann, 1998; Thorne et al., 1999). These tasks are altruistic in nature as they benefit the receiver while providing no direct reproductive benefits to the sterile altruist, and are adaptive if directed towards close relatives (Hamilton, 1972; Holzer et al., 2006). High relatedness within the nest can be maintained through the defense of colony boundaries and nest territory (Bulmer and Traniello, 2002a) as this prevents free exchange of unrelated caste members and facilitates group cohesion (Helantera et al., 2009).

\subsection{Social insects defend nest territory}

Kin-based defenses refer to behaviors that keep out potential intra or interspecific nest intruders, where kin recognition ensures that aggressive acts are not directed toward close relatives (Fisher and Gold, 2003; Zweden and d'Ettorre, 2010; Breed, 2014). Defenses are highly variable among ant and termite species, ranging from overt aggression to more subtle behaviors such as physical separation (Steiner et al., 2007; Helantera et al., 2009). Overt aggression is often expressed through a combination of mechanical and chemical defenses (Shelton and Grace, 1996; Šobotník et al., 2010). Within termite groups the soldier castes are mechanically specialized for combat, possessing enlarged head capsules and mandibles adapted for biting, crushing, slashing or piercing (Prestwich, 1984). Members of the Rhinotermitidae, Serritermitidae and Termitidae attack non-nestmate 
conspecifics not only using their mandibles but may inject irritating, toxic or viscous materials into their opponents (Prestwich, 1984). Soldiers of Globitermes sulphurous take chemical defense a step further by rupturing their own body, secreting a sticky defensive substance that entangles their opponents (Bordereau et al., 1997; Šobotník et al., 2010). In Nasutitermitinae, mandibles are vestigial and soldiers rely primarily on terpenoid defense secretions released by the frontal gland (Prestwich, 1984). In addition to mechanical and chemical defenses soldiers may recruit other nestmates either through body vibrations (i.e. head drumming) or by releasing alarm pheromones from the frontal gland to gain assistance in defense (Šobotník et al., 2010).

Workers of many termite species are also actively involved in colony defense (Shelton and Grace, 1996) by biting, as in the Nasutitermitinae and Rhinotermitidae, or through the use of chemical secretions (Prestwich, 1984; Shelton and Grace 1996). In Skatitermes, workers release toxic fecal liquid onto their opponents (Prestwich, 1984), while older workers of Neocapritermes taracua rupture their own bodies during aggressive displays, releasing a "suicide backpack" of toxic secretions that immobilize their opponents (Šobotník et al., 2012). Such self-sacrifice represents the ultimate altruistic act in social societies (Šobotník et al., 2012). However, as overt forms of defense carry costs that are avoided in other species (Matsuura and Nishida, 2001; Olugbemi 2013). For example, while the subterranean termite Microtermes lepidus demonstrates aggression toward conspecifics that may result in mortality in laboratory assays, field colonies avoid conflict with neighboring nests by building soil barriers at nest entrances, preventing the overlap of foraging trails between conspecifics (Pearce et al., 1990). In response to ant predators or unfamiliar conspecifics, soldiers of the drywood termite Cryptotermes cavifrons and the subterranean termite Reticulitermes speratus will block nest entrance tunnels using their modified flattened, plug-shaped heads. This prevents nestmates within foraging chambers from entering the tunnel, avoiding further conflict (Prestwich, 1984; Matsuura, 2002).

\subsection{Kin-based defenses can be absent}

Kin-based defenses are completely absent in some ant and termite species (Tsutsui et al., 2000; Giraud et al., 2002; Holzer et al., 2006; Pederson et al., 2006; Vargo et al., 2006; 
Helantera et al., 2009). These species form expansive unicolonial societies or supercolonies, where individuals lack intraspecific aggression towards neighboring colonies and there is free exchange of workers and queens between multiple physically separated nests, forming an interconnected population that can extend over a wide geographic range (Giraud et al., 2002; Holzer et al., 2006; Helatera et al., 2009). Populations consist of mixed or extended families of distantly related individuals, such that overall colony relatedness often approaches zero (Vargo, 2003). Cooperative behavior towards individuals of low relatedness appears to present an evolutionary paradox, yet defines some of the most successful ant and termite pest species in the world (Giraud et al., 2002; Pederson et al., 2006; Leniaud et al., 2009; Perdereau et al., 2011). This suggests that a loss of aggression and distinct nest boundaries may have benefits, such as a larger workforce, which can facilitate colony expansion and resource acquisition (Matsuura and Nishida, 2001; Steiner et al., 2007).

How supercolonies form is not well understood. Since unicolonial characteristics are commonly observed in invasive ant and termite populations, supercolonies are thought to be the result of bottleneck effects that occur upon introduction, which leads to the loss of genetic and/or cue diversity thereby reducing the ability to distinguish kin from non-kin (Tsutsui et al., 2000; Giraud et al., 2002; Dronnet et al., 2005; Vargo et al., 2006; Vargo and Husseneder, 2011; Husseneder et al., 2012). However, supercolony formation can still occur within the native range of a species, and kin recognition can still remain intact. In the European ant Lasius austriacus supercolonies, individuals lack aggression but still maintain the ability to discriminate kin from non-kin (Steiner et al., 2007). The invasive Argentine ant (L. humile) forms supercolonies in both its native and introduced ranges, although colony sizes are smaller in the native range (Pederson et al., 2006).

Alternatively, supercolony formation may relate to the reduction of costs associated with territorial defense (Cherix, 1980; Tsutsui et al., 2000). For example, it has been postulated that the formation of supercolonies in the ant Formica paralugubris occurs due to the lack of resources in its native range within the Swiss Jura Mountains (originally supercolonies were identified as F. lugubris, but this species has since been split into two sibling species, only F. paralugubris forms supercolonies) (Cherix, 1980; Bernasconi et al., 2005; Holzer et al, 2006). In contrast, for species with abundant 
resources, such as decaying wood logs, the costs of aggression (injury or death) may outweigh the benefits gained in defending resources (Matsuura and Nishida, 2001; Steiner et al., 2007).

The eastern subterranean termite (Reticulitermes flavipes) feeds on rotting wood logs and is a significant wood-destroying pest in North America (Dronnet et al., 2005; Scaduto et al., 2012; Evans et al., 2013). In areas where this species has been accidentally introduced populations show characteristics of supercolonies, such as lack of intercolony aggression and the formation of expansive colonies (Grace, 1996; Dronnet et al., 2005; Vargo and Husseneder, 2011; Scaduto et al., 2012). Lack of aggression may be related to low genetic diversity of introduced populations and subsequent bottleneck effects, although it is unclear whether native populations are aggressive towards conspecifics or are able form supercolonies.

\subsection{Study species}

\section{Distribution}

The eastern subterranean termite Reticulitermes flavipes (Rhinotermitidae) is native to deciduous forests of the eastern United States but now has a worldwide distribution (Evans et al., 2013). In North America the northernmost part of $R$. flavipes' range is in southern Ontario, where scattered populations are found in approximately 32 urban municipalities, the result of at least three separate introduction events (Myles and Grace, 1991; Scaduto et al., 2012). Populations in Toronto were likely introduced in the 1930's by contaminated shipping cargo from the United States (Grace, 1990). These colonies infest wooden infrastructure and display characteristics suggestive of supercolonies, such as lack of aggression between colonies, high population densities, expansive colony sizes and low allelic diversity at microsatellite loci (Scaduto et al., 2012). In southwestern Ontario populations of $R$. flavipes were discovered in 1929 in Point Pelee National Park and Pelee Island (Grace, 1990; Raffoul et al., 2011). However, the colonies do not infest wooden dwellings but are distributed along sandy shorelines and beneath woody debris (Raffoul et al., 2011). Genetic diversity in colonies from the Pelee region is higher than Toronto populations, suggesting that Pelee populations could be potentially native or have arisen from separate introduction events (Scaduto et al., 2012). 


\section{Biology}

As a subterranean termite, colonies of $R$. flavipes live, feed and nest in underground galleries consisting of extensive foraging tunnels and interconnected feeding and nesting sites (Grace et al., 1989; Evans et al., 2013). Colonies are not fixed in one place but are constantly mobile in search of food sources, which mainly consist of cellulose-containing plant matter (i.e. wood, leaf litter, decaying logs) (Grace et al., 1989). Being prone to desiccation, foragers build shelter tubes above ground, including on living trees to expand foraging territory (Grace and Cooper, 1987). Their propensity for wood consumption makes them important in natural ecosystems for breaking down cellulose material (Evans et al., 2013). In Ontario, populations of $R$. flavipes colonies consist mainly of workers, one to two percent soldiers and multiple secondary reproductives but lack the primary winged alates (king and queen) (Myles and Grace, 1991).

Aggression

Behavioral studies have failed to demonstrate conspecific aggressive responses in some native (Georgia, Polizzi and Forschler, 1998; Massachusets, Bulmer and Traniello, 2002a) or introduced (Toronto, Grace, 1996; France, Perdereau et al. 2011) R. flavipes populations. However, Fisher and Gold (2003) observed aggressive responses between pairings of native colonies from Texas, the level of aggression increasing with geographic distance between colonies. Polizzi and Forschler (1999) suggested polyethism in the worker caste, where only some workers express overt aggression, so one would only observe aggressive behaviors if the appropriate individual worker was present.

\subsection{Objectives of this study}

My aim was to determine if there are behavioral differences in aggression and kin recognition across populations of $R$. flavipes in southern Ontario. My objectives were to:

I. Use behavioral assays to investigate differences in the level of intraspecific aggression and nestmate recognition expressed by $R$. flavipes in Ontario, as a function of distance between populations. 
To test whether populations of $R$. flavipes exhibit aggressive responses towards conspecifics, I conducted behavioral bioassays using populations from Toronto and Pelee Island (390 km apart). The hypothesis being tested was that if aggressive behavior existed in Canadian populations then the level of intercolony aggression would increase with increasing geographic distance between colonies. This was based on the assumption that individuals from distant populations would more easily recognize kin from non-kin than those from neighboring populations, due to their greater genetic dissimilarity. It is known that the Pelee Island populations represent a separate introduction from those in Toronto, and have greater allelic diversity (Scaduto et al., 2012). If, regardless of distance, the populations lack aggression, this could indicate a breakdown in kin discrimination ability following an introduction event, or alternatively R.flavipes may avoid overtly aggressive responses, and discriminate kin from non-kin in more subtle ways.

To test for more subtle forms of nestmate recognition, the length of time paired individuals spent antennating was tested, since antennal contact provides important chemical and tactile information, and tends to be prolonged towards unfamiliar stimuli, such as a non-nestmate (Clément and Bagnères, 1998). Huang et al. (2014) demonstrated that in $R$. chinensis antennal sensillae plays an important role in nestmate recognition, while prolonged antennal bouts towards non-nestmates despite lack of aggression in L. austriacus indicated that nestmate recognition remained intact in supercolonies (Steiner et al., 2007).

In all behavioral assays the level of aggression and antennation time between nonnestmates from the same population but different locale, or non-nestmates from different populations were compared with nestmate pairings.

II. Test whether aggression and nestmate recognition varies as a function of caste, density and colony source.

Generally studies that test for aggression and nestmate recognition in ant or termite species are carried out by placing paired individuals from conspecific colonies into a Petri dish lined with filter paper and all behavioral interactions observed (Polizzi and Forschler, 1999; 1998; Breed, 2003). However, experimental methods frequently vary and this may affect scoring for aggression (Breed, 2003). The number of individuals used 
in an assay may impact the number of aggressive responses or other behaviors observed (Polizzi and Forschler, 1998) so if aggressive polyethism occurs in the worker caste, using a larger number of individuals would increase the chances of selecting an aggressive individual (Polizzi and Forschler, 1999). In addition, both worker and soldier castes participate in nestmate defense, but both castes are rarely tested together. Further, type of caste and number of individuals used may interact with the colony population source. Therefore, I investigated whether scores for aggression and antennation time would vary depending on the type of caste (worker, soldier) and number of individuals used (one-on-one versus five-on-one and five-on-five) across geographic pairings. Aggressive encounters might increase with increasing density or when soldiers, the caste primarily responsible for defense, are present.

III. To compare survivorship between nestmate and non-nestmate pairings and to test whether individuals will sort according to kin and avoid non-kin in a resource foraging design.

To test whether nestmates will sort among kin and avoid non-kin, I used a resource foraging assay adapted from Grace (1996) and Uchima and Grace (2009), that simulates two populations foraging at a single food source. The current study differs from previous studies in using a larger design set-up, a higher number of individuals per pairing and using colonies separated by greater geographic distances. Encounters with other colonies while foraging are expected to be common in nature, so these trials would be more reflective of field conditions than the typical Petri dish trials. If aggressive responses are context-specific, individuals meeting in an open Petri dish arena would be more likely to respond differently than individuals meeting in underground foraging tunnels. Further, $R$. flavipes may avoid aggressive encounters by not intermixing with non-kin, possibly by avoiding overlap of foraging tunnels. The ability to sort among kin would demonstrate an intact recognition system in introduced populations of $R$. flavipes. 


\section{Chapter 2}

\section{Materials and Methods}

\subsection{Termite collection and housing}

To establish laboratory colonies I repeatedly sampled populations from three key locations in southern Ontario: Toronto, Point Pelee National Park $\left(41.588^{\circ} \mathrm{N},-82.326^{\circ}\right.$ W) and Pelee Island $\left(41.481^{\circ} \mathrm{N},-82.377^{\circ} \mathrm{W}\right)$ between May - October, 2015.

Corrugated roll traps consisting of a single face, two-ply corrugated cardboard roll (10 $\mathrm{cm} \times 10 \mathrm{~cm})$ with a plywood lid $(15 \mathrm{~cm} \times 15 \mathrm{~cm})$ (Figure 2.1$)$ are an efficient attractant to foraging termites, serving as a source of food, shelter and moisture (Grace 1989). Therefore roll traps were buried three centimeters below the soil surface in areas of suspected termite activity (Figure 2.1). In order to increase the potential of collecting individuals representing two distinct colonies within a population at each of the three primary sites, traps were set out at two locales $>1.5 \mathrm{~km}$ apart, as a distinct colony within a population typically has a radius of approximately $800 \mathrm{~m}-1 \mathrm{~km}$ (Raffoul et al., 2011). In Point Pelee National Park traps were set at both Gate Beach and Northwest Beach (1.5 $\mathrm{km}$ apart), along sandy shorelines underneath fallen woody debris in mild to moderate stages of decay (Figure 2.1). On Pelee Island traps were set around a decaying woodpile near the Ivey Research Station, as well as $200 \mathrm{~m}$ away underneath rotting wooden logs (Figure 2.1). Traps were also set $3 \mathrm{~km}$ away at Lighthouse Point underneath large wooden pillars and gravel sediment. In Toronto both trapping sites were in the Danforth area (Aetna Pest Control requested that exact locations not be disclosed due to client confidentiality). At Toronto location A traps were set within a flowerbed of an infested home (Figure 2.1), and at location B traps were set along a narrow flowerbed and fencerow beside a second infested home (location B) $7 \mathrm{~km}$ away.

After one to three weeks I collected any trap rolls with active termite activity in $6 \mathrm{~L}$ plastic Tupperware containers and transported to the University of Western Ontario. Individuals collected in rolls largely consisted of workers, although proportions varied with location: In Point Pelee National Park and Pelee Island collections consisted of approximately $95 \%$ workers, $1 \%$ soldiers and $4 \%$ reproductives, while in Toronto 
collections consisted of $98 \%$ workers, $1.5 \%$ soldiers and $0.5 \%$ reproductives. I sampled each site 3-5 times during the field season due to frequent shortage of soldiers when conducting behavioral trials. Overall between 38,000 - 40,000 termites were collected throughout the field season. Behavioral assays usually began within a month of collection in the field. Since colony aggression in $R$. flavipes may decrease with length of time that termites are kept in a lab (Clément, 1986), colonies freshly collected in the field were preferred.

Termites were housed within a walk-in environmental chamber and kept under normal room temperature conditions $\left(24 \pm 1^{\circ} \mathrm{C}, 60 \% \mathrm{RH}\right)$ under a $16 \mathrm{~L}: 8 \mathrm{D}$ photoperiod. All containers were filled with $1 \mathrm{~L}$ of field-collected substrate and inert sand. One hundred and twenty grams of damp maple and oak shavings carved from solid wood were added as a shelter and food source, along with plywood pieces and a plywood board made of softwood (cedar). Both solid wood and plywood were purchased at a hardware store. Moisture levels were maintained through regular watering 2-3x per week.

\subsection{Behavioral assays}

\section{Behavioral assay set-up}

I gently sifted soil from colony housing containers through a makeshift sieve and then brushed exposed termites onto weigh boats using a soft paintbrush. Since the set-up of each assay was the same regardless of the number of termites, type of caste and colony origin, the description of an assay testing the interactions of two workers is used here as an example of the general protocol. One of the two individuals was marked with acrylic paint on the dorsal surface of the abdomen tip and then both were held for 1 hour in individual $3.5 \mathrm{~cm}$ Petri dishes lined with moist paper, one designated as the resident the other as the intruder. The individual being marked (resident or intruder) was alternated between replicates. After the acclimation period the intruder was introduced into the resident's Petri dish and all interactions filmed over a 5-7 minute period using a Sony HDR-CX700 camera in nightshot mode, as assays were performed in an unlit environmental chamber during the dark cycle. After each replicate the Petri dishes were rinsed with water, ethanol and dish soap to remove potential chemical residues. 
Scoring

Behavioral interactions (defined as any point of contact between two individuals) were later analyzed in detail using VLC media player. Each aggressive interaction was classified by type and given a numeric value (See Table 2.1) so that an overall mean aggression score was obtained, with resident and intruder responses scored separately. Antennation time (s) was calculated by subtracting the start and end time of antennal contact using VLC media player and calculating the mean antennation time for resident or intruder for the observation period. Other interactions that were noted but not scored included oscillatory body movements (rapid forward-backward thrusting of the body), grooming, startle reactions (body pushed back rapidly) and avoidance (quickly turning in the opposite direction). 

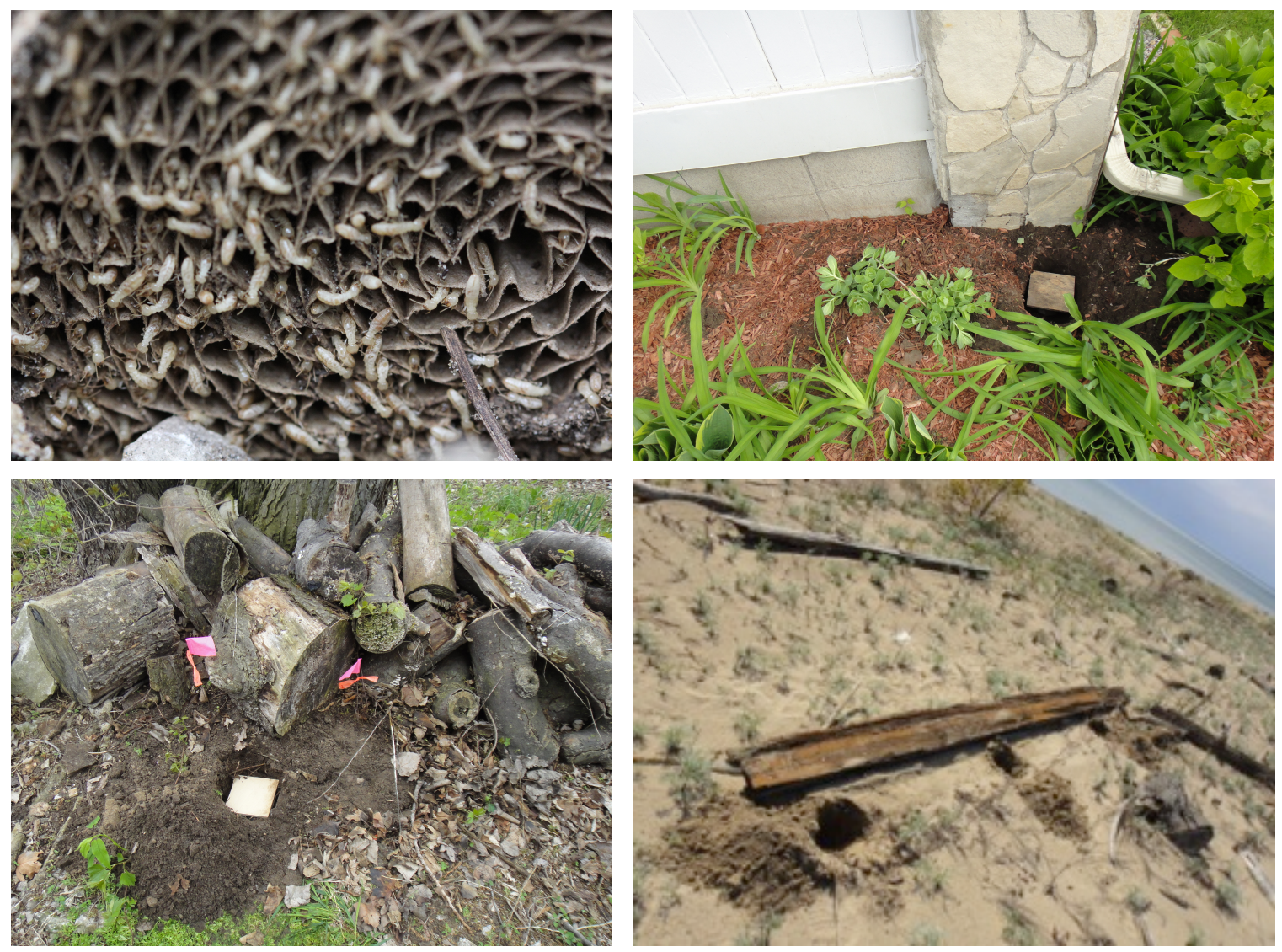

Figure 2.1: Cardboard roll trap collection method. A single face, two-ply corrugated cardboard roll (top left) was used as an attractant to termites, and buried one inch below the soil surface with a plywood lid (top right, bottom left). Traps were buried in in three main sites: Toronto (top right), Pelee Island (bottom left), Point Pelee National Park (bottom right). 
Table 2.1: Classification of behavioral responses and relative intensity of aggression scoring scale used in behavioral assays of the Eastern subterranean termite $R$. flavipes to obtain a 5-minute mean aggression score.

Behavior (worker)

Antennation: termite makes contact with the body of the other termite

\section{Behavior (soldier) Aggression score}

0

Mandible flare: Head

$+1$

oriented towards other

individual with

mandibles widened

Mandible flare, lunge

$+2$

forward widened, while lunging towards the other

individual
Biting: mandible-mandible or side-side biting between individuals.
Biting: mandibles

widen and close, bite other individual 
One-on-One Behavioral Assays: Geographic Distance

To determine whether intra-specific aggression and antennation time would vary between colonies of varying geographic distance the behaviors of worker-worker pairings from the three sites were compared with those of nestmate pairings, which served as controls. For short distance inter-population comparisons the following assays were carried out: $\mathrm{TO}_{\mathrm{A}}-\mathrm{TO}_{\mathrm{B}}, 6 \mathrm{~km}$ vs $\mathrm{TO}_{\mathrm{A}}-\mathrm{TO}_{\mathrm{A}}, 0 \mathrm{~km} ; \mathrm{PI}_{\mathrm{A}}-\mathrm{PI}_{\mathrm{B}}, 3 \mathrm{~km}$ vs $\mathrm{PI}_{\mathrm{A}}-\mathrm{PI}_{\mathrm{A}}, 0 \mathrm{~km}$. The following longer distance assays were conducted: Toronto with Point Pelee $\left(\mathrm{TO}_{\mathrm{A}}-\mathrm{PP}\right.$, $360 \mathrm{~km}$ ) and Toronto with Pelee Island $\left(\mathrm{TO}_{\mathrm{A}}-\mathrm{PI}, 390 \mathrm{~km}\right)$. Assays using pairings of different caste types (worker-worker, worker-soldier, soldier-soldier) were also carried out to determine whether caste influences intraspecific aggression or antennation time. The number of replicates for each different assay is indicated in Table 2.2. 
Table 2.2 Number of replicates for geographic distance pairings. One-on-one residentintruder pairings of different castes $(\mathrm{ww}=$ worker-worker, $\mathrm{ws}=$ worker-soldier, $\mathrm{ss}=$ soldier-soldier $)$ and colony source $(\mathrm{NM}=$ nestmate, $\mathrm{NNM}=$ non-nestmate $)$.

\begin{tabular}{|c|c|c|}
\hline Caste Pairing & Colony Source & \# of Replicates \\
\hline ww & $\mathrm{TO}-\mathrm{TO}(\mathrm{NM})$ & 10 \\
\hline $\mathbf{w w}$ & PI - PI (NM) & 10 \\
\hline ww & TO - PI (NNM) & 20 \\
\hline ww & $\mathrm{TO}_{\mathrm{A}}-\mathrm{TO}_{\mathrm{B}}(\mathrm{NNM})$ & 10 \\
\hline ww & TO - PP (NNM) & 10 \\
\hline ww & $\mathrm{PI}_{\mathrm{A}}-\mathrm{PI}_{\mathrm{B}}(\mathrm{NNM})$ & 10 \\
\hline ws & $\mathrm{TO}-\mathrm{TO}(\mathrm{NM})$ & 10 \\
\hline ws & PI - PI (NM) & 10 \\
\hline ws & TO - PI (NNM) & 20 \\
\hline ss & $\mathrm{TO}-\mathrm{TO}(\mathrm{NM})$ & 10 \\
\hline ss & PI - PI (NM) & 10 \\
\hline ss & TO - PI (NNM) & 20 \\
\hline TOTAL & & 150 \\
\hline
\end{tabular}




\section{Effects of Density:}

To determine whether there were effects on the frequency of aggressive responses or antennation time between nestmates and non-nestmates in five-on-one and five-on-five pairings, Toronto - Pelee Island combinations using different castes (worker-worker, worker-soldier, soldier-soldier) were compared, with nestmate pairings serving as a control. In five-on-one pairings, resident-to-resident (nestmate) pairings were compared with resident-to-intruder (non-nestmate) pairings, while in five-on-five pairings intruderto-intruder (nestmate) and intruder-to-resident (non-nestmate) pairings were compared in addition to resident-to-resident and resident-to-intruder pairings. Secondly, to determine whether there were any density effects on aggression or antennation, one-on-one nonnestmate (resident-to-intruder and intruder-to-resident) were compared to five-on-one and five-on-five non-nestmate pairings (see Figure 2.2). A total of 30 assays were carried out for each density (one-on-one, five-on-one and five-on-five), with 10 replicates per caste type combination (worker-worker, worker-soldier or soldier-soldier).

\section{Soldier agitation and soldier crushing trials}

Due to lack of aggressive responses in my behavioral assays, two further experiments were performed to determine whether agitating a soldier termite with a paintbrush or by alarm pheromone released through crushing a soldier's head induced aggression. For agitation assays, both resident and intruder soldiers were repeatedly tapped with a paintbrush on their mandibles for 30 seconds and the one-on-one interactions were observed over 5 -minutes. As crushed soldiers might release alarm pheromone, potentially inducing responses such as mandible flaring and head banging in the other soldier, the head of the intruder soldier was crushed and responses of the resident to the crushed soldier were recorded over a 5-minute interval.

\subsection{Resource Foraging Design}

\section{Seven-Day Resource Foraging Design Set-up}

To determine if the integrity of colonies originating from different geographic sites would be maintained, I set up a longer-term assay consisting of a three-compartment chamber meant to simulate two colonies foraging at a single resource (Figure 2.3). 
The compartments were two 2.3 L Tupperware containers filled with moistened inert sand, joined by eight small glass tubes to a central food resource containing moist sand, $60 \mathrm{~g}$ of water soaked maple and oak shavings, two corrugated cardboard rolls and small wooden blocks. Two longer glass tubes also joined the left and right compartments directly. In any given assay, 1,000 workers were used and prior to the assay 500 were fed plain Whatman \#7 filter paper while the other 500 were fed filter paper stained with $0.1 \%$ w/w Nile Blue A cell stain for 2-3 days (Figure 2.4). The two groups were either nestmates (500 stained and 500 unstained from the same colony) or non-nestmates (500 stained and 500 unstained from different colonies). Nile blue $\mathrm{A}$ is a preferred stain in mark-release recapture experiments, as it has no effect on termite mortality and is long lasting (14-21 days) (Su et al., 1999). Although this staining approach did not affect individual mortality in my preliminary tests, in inter-colony pairings the group stained was alternated to minimize any potential effects. After stained and unstained groups were placed in the left or right compartment (alternated between replicates), it would usually take one to two days for all individuals to tunnel into the moist sand. For the duration of the assay it was possible to observe individuals moving between tubes to different compartments, often engaging in antennation or oscillatory body movements. After seven days the total number of live individuals in different sections of the test arena were determined, as well as the \% survivorship of each group, and the proportion of individuals recovered in their natal/home base or in another compartment. To ensure all individuals were counted termites were carefully separated from substrate using a sieve and paintbrush, and collected using an aspirator. Ten individuals were counted at a time to ensure consistency. The following combinations, with four replicates each, were used: Toronto - Toronto $\left(\mathrm{TO}_{\mathrm{A}}-\mathrm{TO}_{\mathrm{A}}\right)$, Pelee Island - Pelee Island $\left(\mathrm{PI}_{\mathrm{A}}-\mathrm{PI}_{\mathrm{A}}\right)$ and Toronto - Pelee Island $\left(\mathrm{TO}_{\mathrm{A}}-\mathrm{PI}_{\mathrm{A}}\right)$. In addition, colonies separated by shorter geographic difference distances were tested: Toronto $\mathrm{A}-$ Toronto $\mathrm{B}\left(\mathrm{TO}_{\mathrm{A}}-\mathrm{TO}_{\mathrm{B}}\right)$ and Point Pelee Pelee Island $\left(\mathrm{PP}-\mathrm{PI}_{\mathrm{A}}\right)$, with two replicates per pairing.

\section{Two-Day Resource Foraging Design Set-up}

In seven-day resource assays, worker mortality was higher in inter-colony pairings than between same colony (nestmate) pairings, possibly the result of starvation if there was reduced feeding in the presence of non-nestmates. Therefore, a two-day shared-resource 
assay was set up using a $9.5 \mathrm{~cm}$ Petri dish divided into three compartments

(Figure 2.5). The left and right compartments were filled with moist sand, while the middle compartment contained moistened Whatman \#7 filter paper as a food resource. The following pairings were tested: $\mathrm{TO}_{\mathrm{A}}-\mathrm{TO}_{\mathrm{A}}$ and $\mathrm{PI}_{\mathrm{A}}-\mathrm{PI}_{\mathrm{A}}$ as nestmate pairings and $\mathrm{TO}_{\mathrm{A}^{-}}$ $\mathrm{PI}_{\mathrm{A}}$ as the non-nestmate pairing, with 15 stained and 15 unstained individuals in the left or right compartments. The number and position of stained and unstained live workers was recorded after 48 hours (a period considered too short for a worker to die of starvation) to determine displacement and the proportion of survivors. There were 15 replicates for each of the three paired combinations.

\subsection{Statistical Analyses}

All statistical analyses were carried out using the $\mathrm{R}$ statistical programming platform (R Core Team, 2015; version 3.2.2). All Petri dish-based behavioral assays were analyzed using one-way ANOVA followed by Tukey's HSD test. Mean aggression score and antennation time (s) served as response variables, with colony origin (nestmate or non-nestmate) as a factor. Movement of termites between compartments in seven-day and two-day resource design experiments was analyzed using quasibinomial logistic regression to account for overdispersion in the model (dispersion factor $=22.5)$. The proportions of survivors in resource experiments were arcsin-transformed before analysis using one-way ANOVA, and significant differences analyzed using Tukey's HSD test. In both seven-day and two-day resource design experiments, survivorship served as the response variable, with colony origin (nestmate or non-nestmate) as factor. 


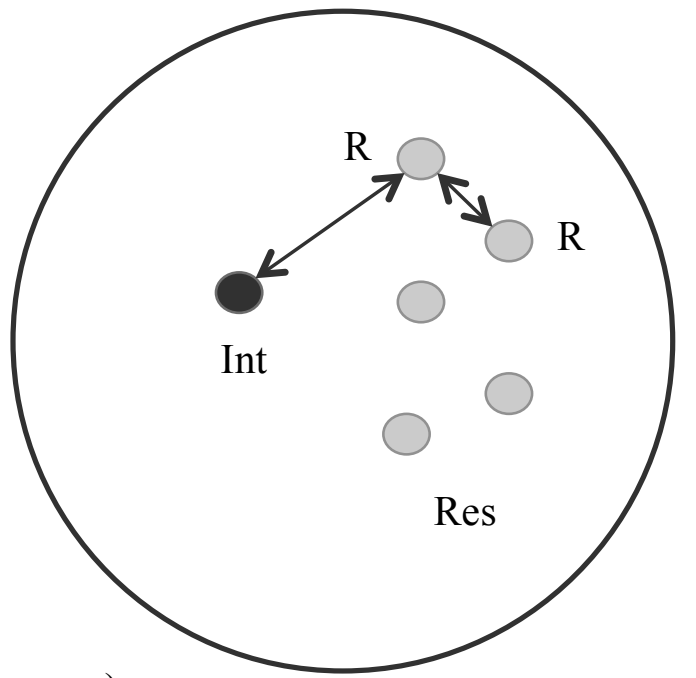

a)

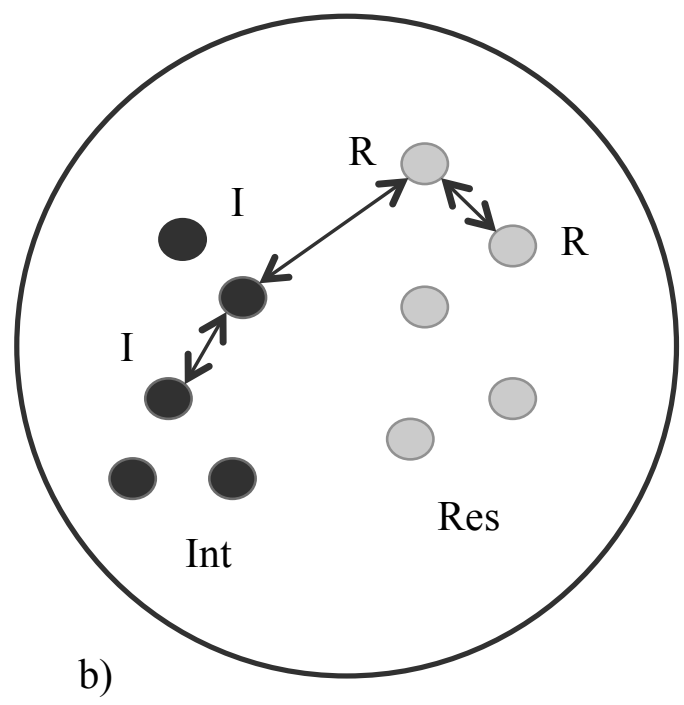

Figure 2.2. Petri dish $(3.5 \mathrm{~cm})$ behavioral assay set-up for a) five-on-one and b) five-onfive colony pairings. In five-on-one pairings, antennation and aggression scores were calculated between Resident (Res) - Intruder (Int) (non-nestmate pairings) and Resident - Resident (nestmate). In five-on-five pairings interactions between Intruder - Intruder were also included.. 


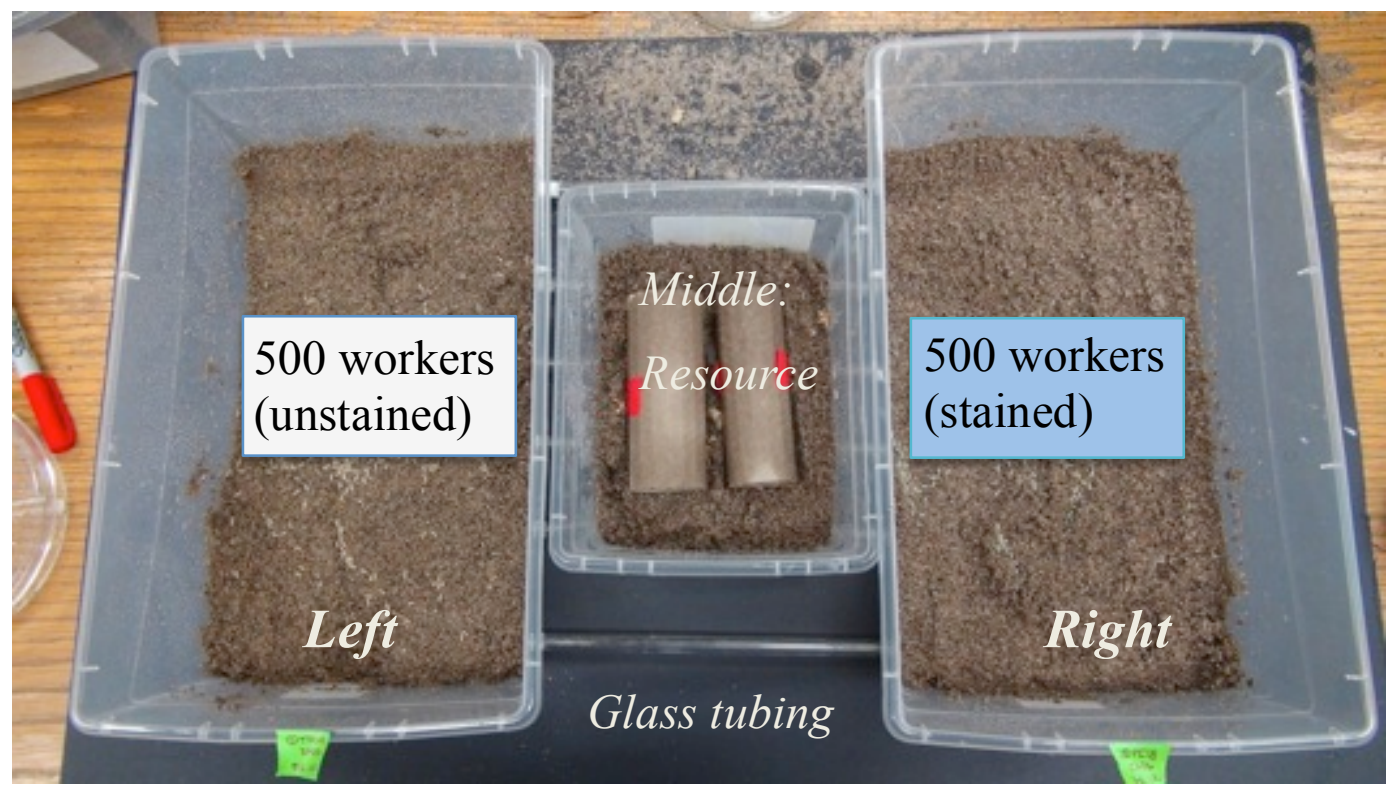

Figure 2.3. Seven-day resource foraging design set-up. Left and right Tupperware containers were filled with moist sand and connected directly or to the middle resource by glass tubing. 500 workers, either stained or unstained were added to the left or right container. The middle resource contained two cardboard rolls and moist wood shavings as a food resource. 


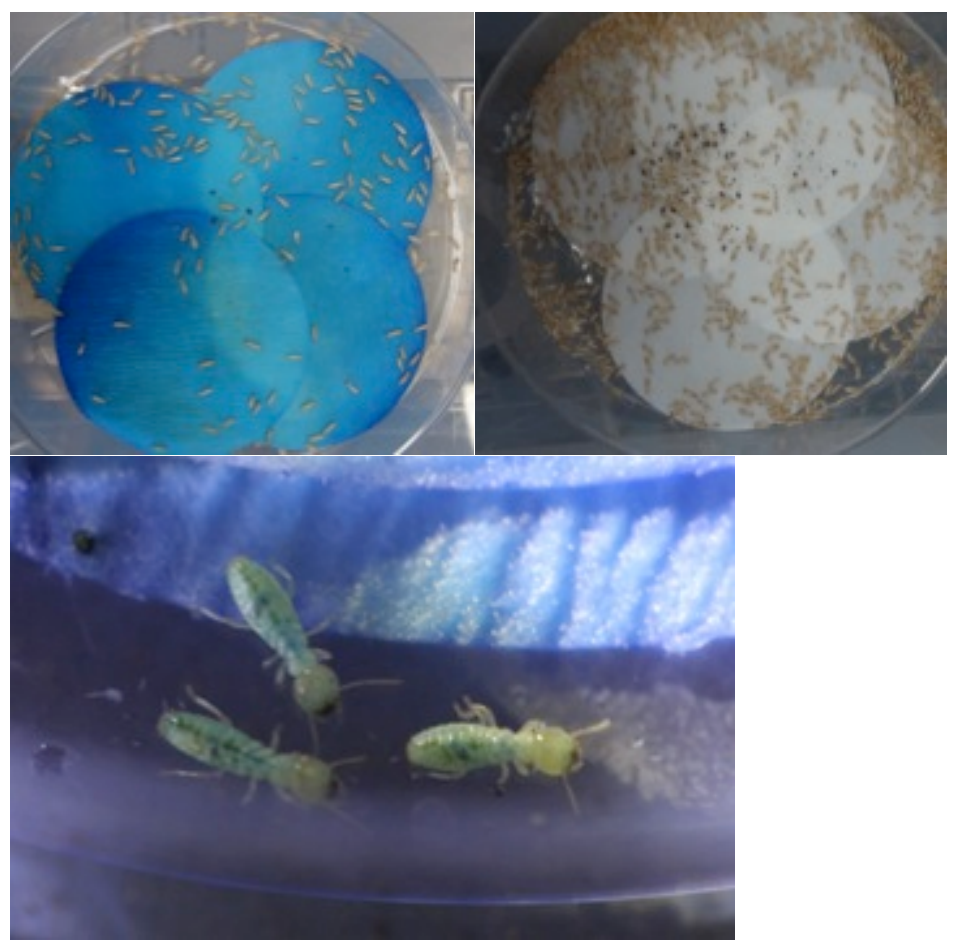

Figure 2.4. Nile Blue A cell stain. Individual workers were divided into two groups and fed stained (top left) or unstained filter paper (top right). After 2-3 days stained individuals would turn a blue color (bottom photo). 


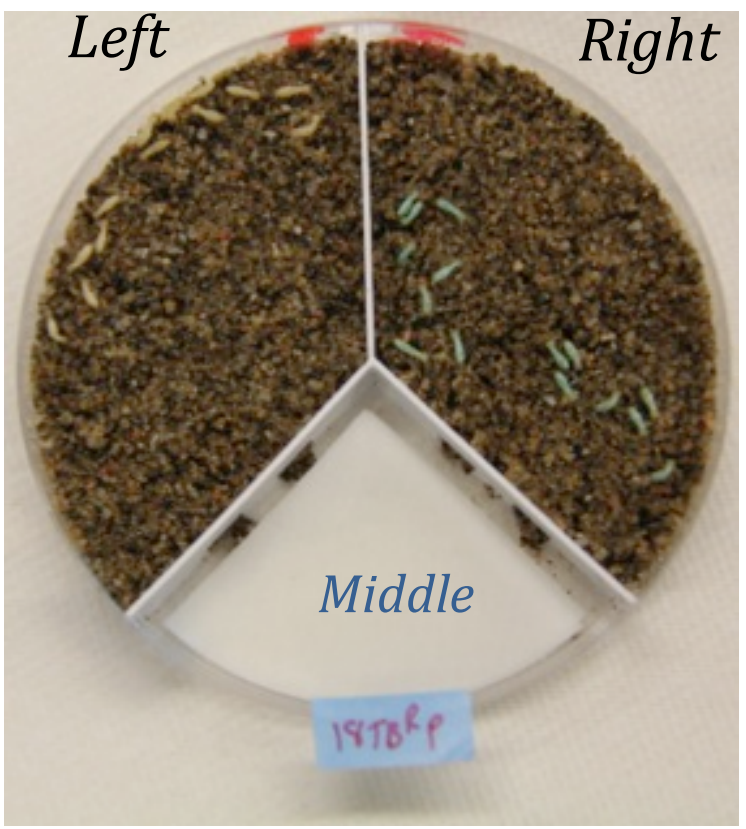

Figure 2.5. Two-day resource foraging design set-up, using a $9.5 \mathrm{~cm}$ Petri dish divided into three compartments. 15 stained and 15 unstained individuals were added to the left and right compartments containing moist sand, connected to a middle food resource containing moist filter paper. 


\section{Chapter 3}

\section{Results}

\subsection{Behavioral assays}

One-on-One Behavioral Assays: Geographic Distance

Aggressive behaviors were almost absent in one-on-one worker-worker trials across all geographic pairings between Toronto colonies (Table 3.1). In TO-TO nestmate pairings $0.4-1.1 \%$ of interactions were aggressive, with $0 \%$ aggression for $\mathrm{TO}_{\mathrm{A}}-\mathrm{TO}_{\mathrm{B}}$ and $\mathrm{TO}-\mathrm{PP}$ pairings and $0-0.5 \%$ aggression for TO-PI non-nestmate pairings (Table 3.1). There were no significant differences in mean aggression score between nestmate (TO-TO) and non-nestmate (TO-PI) pairings for both the residents' response to an intruder and intruders' response to a resident (Table 3.2). Similar to Toronto pairings, aggressive encounters were almost absent across all geographic pairings between Pelee Island colonies (Table 3.1), and there were no differences in mean aggression score between nestmate and non-nestmate pairings for either the resident or intruder response (Table 3.2). In TO-TO caste pairings $2.50-3.33 \%$ of worker-soldier nestmate pairings were aggressive, with a slight increase of $1.1-8.6 \%$ for non-nestmate pairings (TO-PI). In PI-PI worker-soldier nestmate pairings 3.7 - 7.4\% were aggressive compared to 1.5 $11.2 \%$ of non-nestmate pairings (PI - TO). For soldier-soldier pairings $2.9-3.9 \%$ of nestmate (TO-TO) pairings were aggressive compared to $8.1-8.8 \%$ for non-nestmates (TO-PI) (Table 3.1). There were no significant differences in mean aggression score between nestmate and non-nestmate pairings for both worker-soldier and soldier-soldier caste pairings (Table 3.2, see Appendix A). The most common aggressive responses for soldiers were mandible flaring, with vary rare instances of lunge flares and biting. Occasionally mandible gaping was observed for workers but no lunge flares or biting was ever observed.

For Toronto colony pairings (TO-TO, $\mathrm{TO}_{\mathrm{A}}-\mathrm{TO}_{\mathrm{B}}, \mathrm{TO}-\mathrm{PP}, \mathrm{TO}-\mathrm{PI}$ ) there were no differences in the resident's antennation time regardless of geographic distance, $\mathrm{F}(3,36)$ $=2.82, \mathrm{p}=0.05$, although antennation was higher towards non-nestmates $\mathrm{TO}_{\mathrm{A}}-\mathrm{TO}_{\mathrm{B}}$ and TO-PP compared to TO-TO (Figure 3.1). Intruder termites had significantly higher 
antennation scores for TO-PP pairings compared to TO-PI pairings $(\mathrm{F}(3,36)=2.97$, $\mathrm{p}<0.05)$. Antennation time was no different for TO-TO nestmates compared to the furthest distance non-nestmate pairing TO-PI (Figure 3.1). In Pelee colony pairings (PI-PI, $\left.\mathrm{PI}_{\mathrm{A}}-\mathrm{PI} \mathrm{B}_{\mathrm{B}}, \mathrm{PI}-\mathrm{TO}\right)$ there were no significant differences in the resident's antennation time regardless of whether Pelee Island workers were paired with nestmates or nonnestmates, $(F(2,25)=0.87, p=0.43)$, although antennation time was slightly higher for PI-TO pairings compared to $\mathrm{PI}_{\mathrm{A}}-\mathrm{PI} \mathrm{B}_{\mathrm{B}}$ and PI-PI (Figure 3.2). Differences in intruder antennation time between nestmates and non-nestmates were also non-significant, $(\mathrm{F}(2,25)=1.41, \mathrm{p}=0.26)$. Antennation time was slightly higher for $\mathrm{PI}-\mathrm{TO}$ and $\mathrm{PI}_{\mathrm{A}}-\mathrm{PI}_{\mathrm{B}}$ compared to PI-PI nestmate pairings (Figure 3.2). In caste pairings there were no significant differences in the resident's response to an intruder and the intruder's response to a resident across all worker-soldier and soldier-soldier assays (Table 3.3, Figure 3.3, Figure 3.4). The total number of antennations over the 5-minute observation interval varied with each replicate (Table 3.4), ranging from frequent to little or no interaction. Soldiers tended to interact less than workers, and replicates were repeated if there were zero antennation responses, which occurred in 5 of 40 soldier-soldier replicate trials. 
Table 3.1. Percentage of aggressive responses (\% aggr. responses), mean aggression score (MAS) and total \# of interactions for one-on-one pairings with Toronto (TO), Pelee Island (PI) or Point Pelee (PP) pairings $(\mathrm{n}=10$ per pairing). $\mathrm{RI}=$ Resident response to intruder, IR = Intruder response to resident, ww = worker-worker, ws $=$ worker-soldier, ss $=$ soldier-soldier.

\begin{tabular}{cccccc}
\hline ww & $\begin{array}{c}\text { Total \# } \\
\text { interactions }\end{array}$ & $\begin{array}{c}\text { \% aggr. } \\
\text { responses }\end{array}$ & MAS & $\begin{array}{c}\text { \% aggr. } \\
\text { response }\end{array}$ & MAS \\
TO - TO & 275 & 0.4 & 1.00 & 1.1 & 1.01 \\
TO $_{\mathrm{A}}-\mathrm{TO}$ B & 126 & 0 & 1.00 & 0 & 1.00 \\
TO - PP & 160 & 0 & 1.00 & 0 & 1.00 \\
TO - PI & 186 & 0 & 1.00 & 0.5 & 1.01 \\
PI - PI & 275 & 0.4 & 1.00 & 1.1 & 1.01 \\
PI - PI & 139 & 0.7 & 1.00 & 0 & 1.00 \\
PI - TO & 195 & 0 & 1.00 & 0 & 1.00 \\
\hline ws & & & & & \\
TO - TO & 120 & 2.5 & 1.03 & 3.3 & 1.03 \\
PI - TO & 134 & 1.5 & 1.01 & 11.2 & 1.10 \\
PI - PI & 136 & 3.7 & 1.03 & 7.4 & 1.06 \\
TO - PI & 93 & 8.6 & 1.10 & 1.1 & 1.03 \\
\hline ss & & & & & \\
TO - TO & 102 & 2.9 & 1.05 & 3.92 & 1.05 \\
PI - TO & 120 & 10.0 & 1.13 & 11.7 & 1.18 \\
PI - PI & 147 & 3.4 & 1.05 & 6.8 & 1.10 \\
TO - PI & 148 & 8.8 & 1.07 & 8.1 & 1.08 \\
\hline
\end{tabular}


Table 3.2. Summary of one-way independent ANOVA for mean aggression score of the resident termite in response to an intruder and intruder termite in response to a resident, comparing differences between situations where individuals were from the same (T-T, P-P) or different (T-P, P-T) colony. Interactions were between worker-worker (ww), worker-soldier (ws) or soldier-soldier (ss) pairings.

\begin{tabular}{llllll}
\hline & Pairing & df & F & p \\
\hline Resident response to intruder & ww & 3,36 & 1.80 & 0.17 \\
& ws & 3,36 & 1.80 & 0.17 \\
& ss & 3,36 & 1.35 & 0.27 \\
Intruder response to resident & ww & 3,36 & 1.53 & 0.22 \\
& & & & \\
& ws & 3,36 & 0.80 & 0.50 \\
& & & & & \\
& ss & 3,36 & 0.84 & 0.48 \\
\hline
\end{tabular}



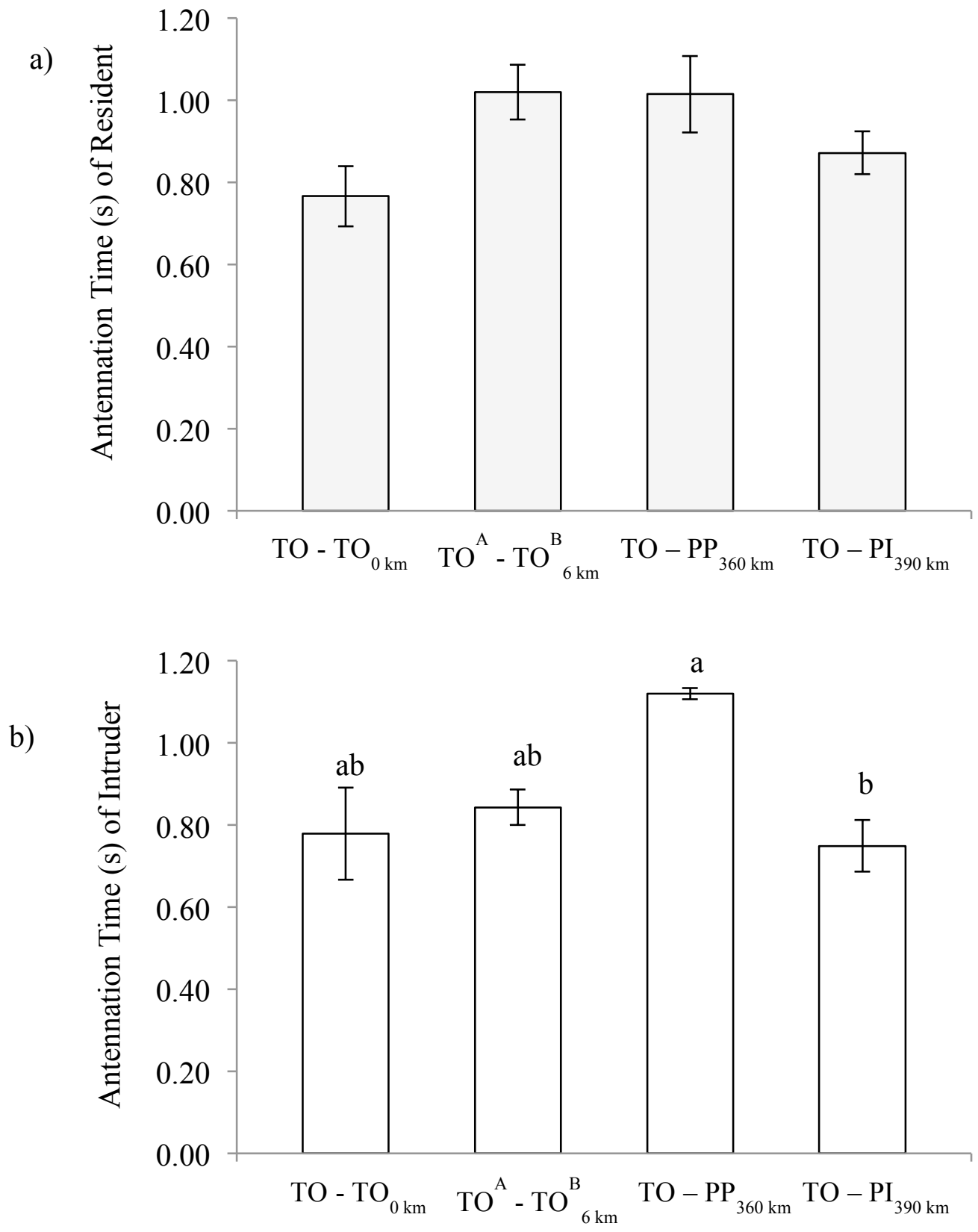

Figure 3.1. Mean antennation time ( $\pm \mathrm{SE}$ ) for one-on-one worker-worker pairings between nestmates $(\mathrm{TO}-\mathrm{TO})$ and non-nestmates $\left(\mathrm{TO}_{\mathrm{A}}-\mathrm{TO}_{\mathrm{B}}, \mathrm{TO}-\mathrm{PP}, \mathrm{TO}-\mathrm{PI}\right)$. Fig. 3.1a represents antennation time of resident in response to intruder, Fig. 3.1b antennation time of intruder in response to resident. $n=40,10$ replicates per pairing 
a)

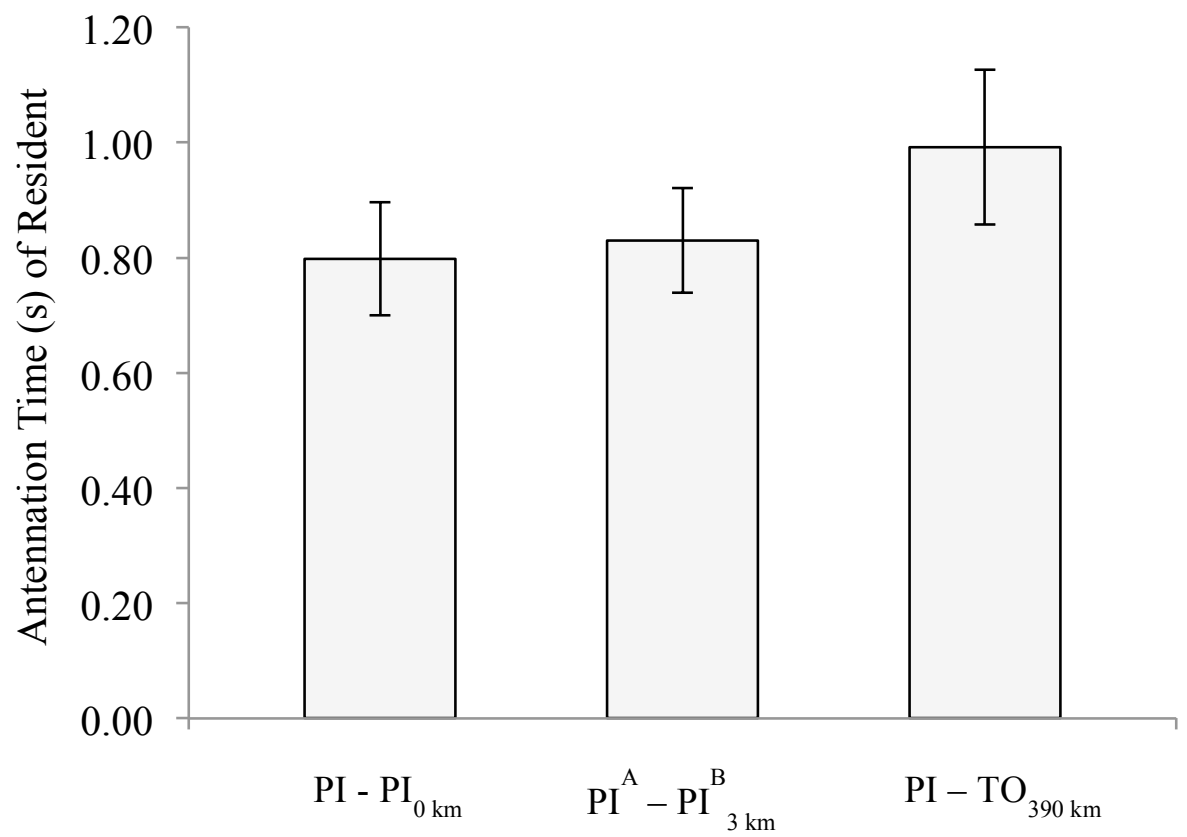

b)

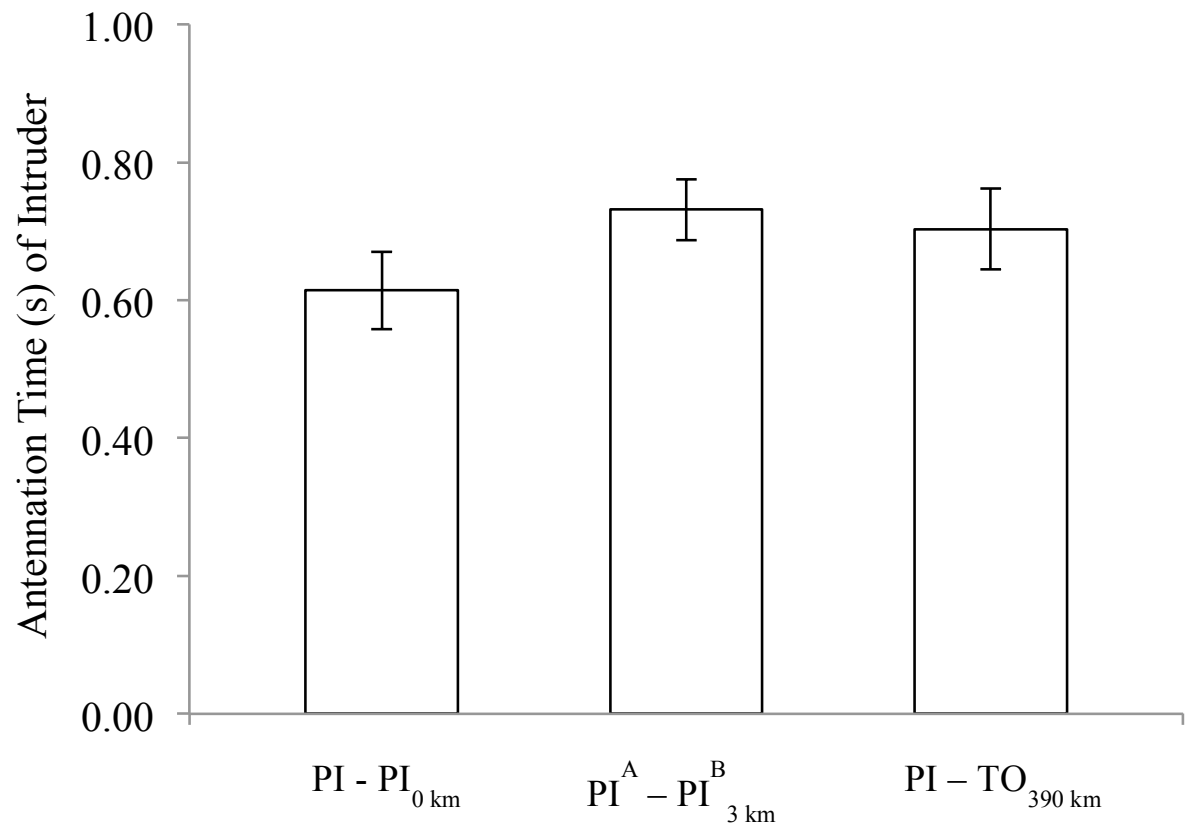

Figure 3.2. Mean antennation time for one-on-one worker-worker pairings comparing a) the Pelee Island resident response to intruder and b) Pelee Island intruder response to resident at various geographic distances. $n=30,10$ replicates per geographic pairing. 
a)

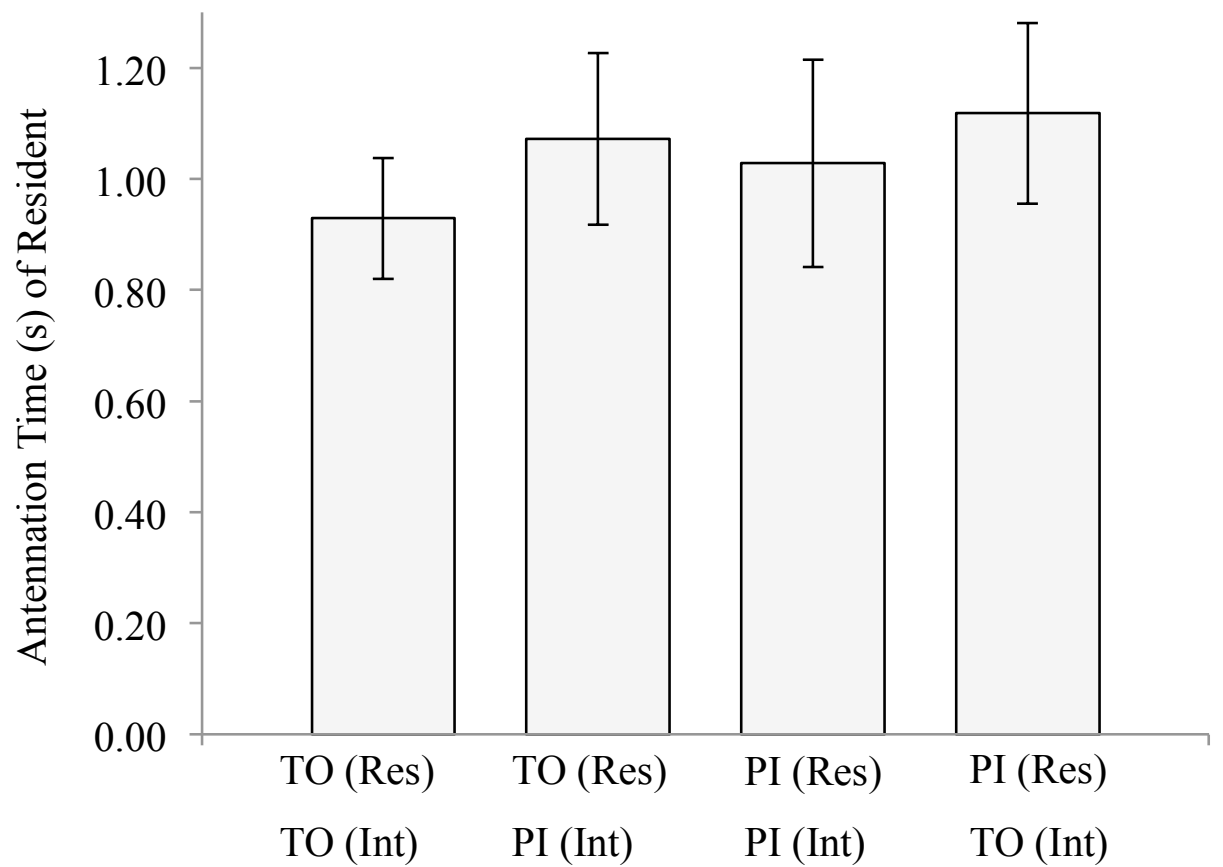

b)

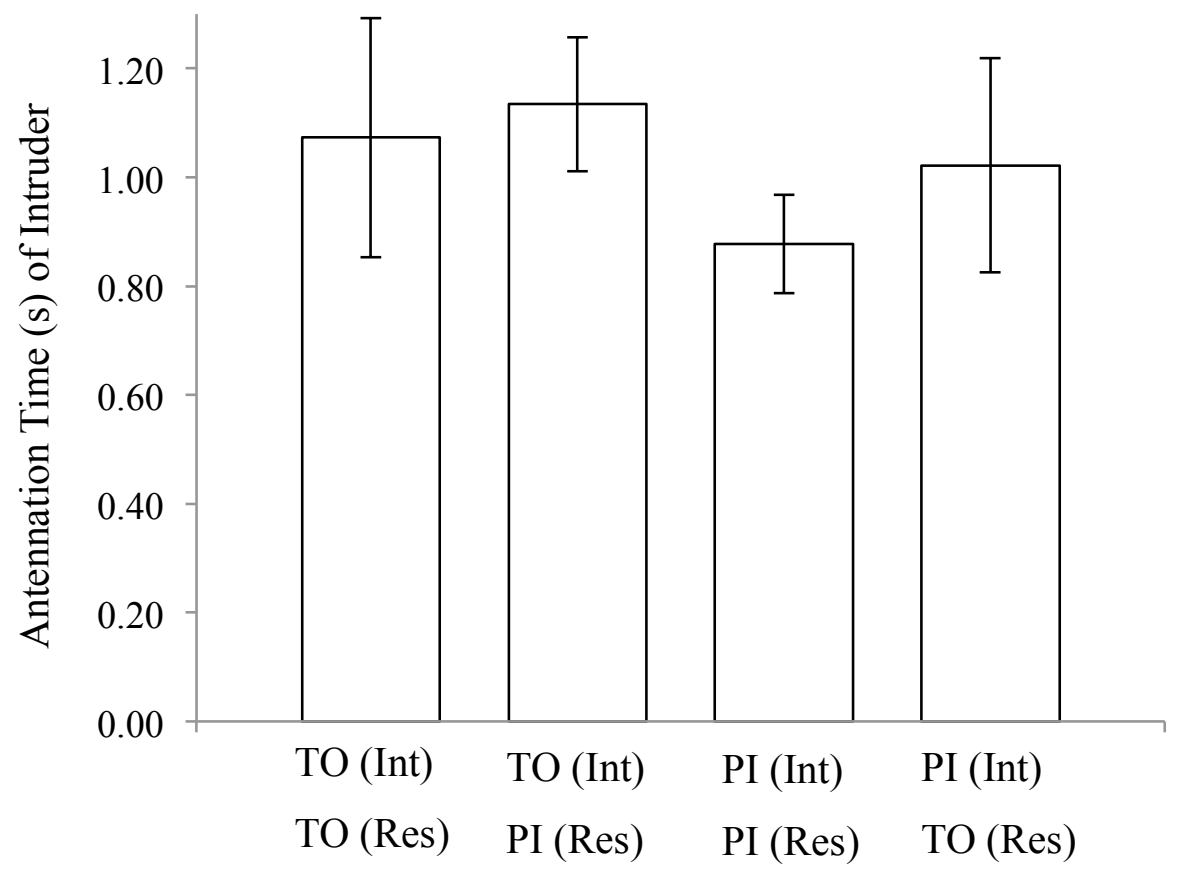

Figure 3.3. Mean antennation time ( $\pm \mathrm{SE}$ ) for one-on-one worker-soldier pairings between nestmates (TO - TO, PI - PI) and non-nestmates (TO - PI, PI - TO). Fig. 3.3a represents antennation time of resident in response to intruder, Fig. 3.3b antennation time of intruder in response to resident. $n=40,10$ replicates per pairing. 
a)

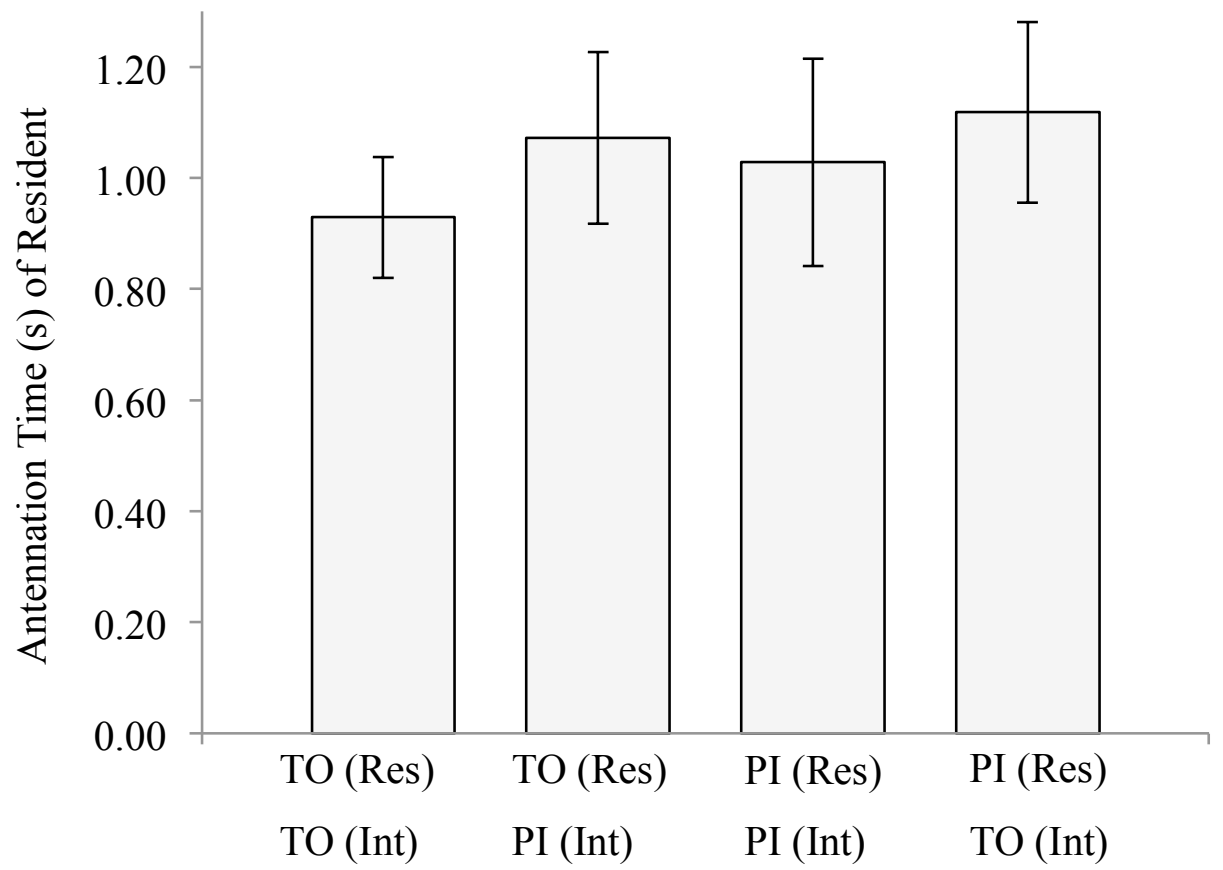

b)

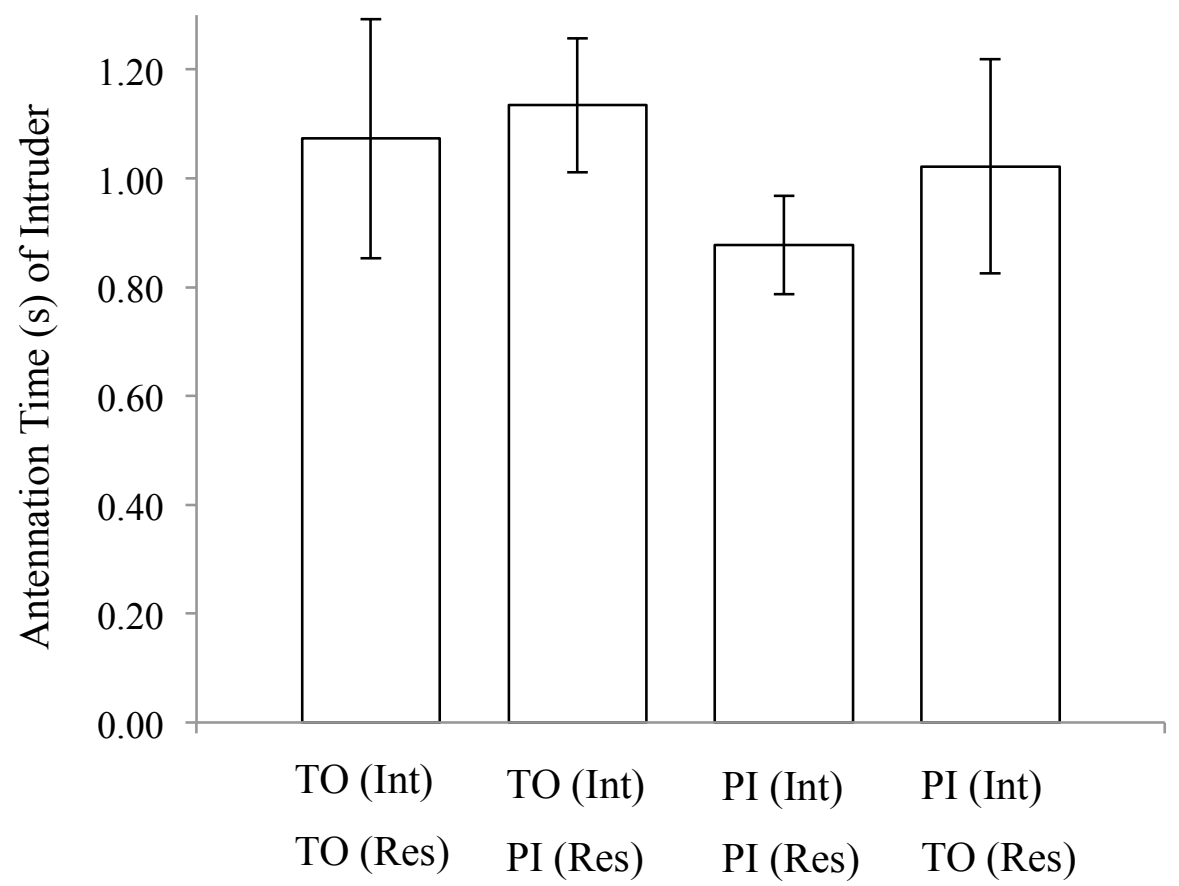

Figure 3.4. Mean antennation time $(\mathrm{s} \pm \mathrm{SE}$ ) for 1-on-1 soldier-soldier pairings between nestmates (TO - TO, PI - PI) and non-nestmates (TO - PI, PI - TO). Fig. 3.4a represents antennation time of resident in response to intruder, Fig. 3.4b antennation time of intruder in response to resident. $n=40,10$ replicates per pairing. 
Table 3.3. Summary of one-way independent ANOVA for mean antennation time (s) of the resident termite in response to an intruder and intruder termite in response to a resident in one-on-one pairings, comparing differences between situations where individuals were from the same (TO-TO or PI-PI) colony or different (TO-PI or PI-TO) colonies. Interactions were between worker-worker (ww), worker-soldier (ws) or soldiersoldier (ss) pairings.

\begin{tabular}{llllll}
\hline & Pairing & df & F & p \\
\hline Resident response to intruder & ww & 3,36 & 1.00 & 0.35 \\
& ws & 3,36 & 0.07 & 0.85 \\
& & & & \\
Intruder response to resident & ww & 3,36 & 0.71 & 0.55 \\
& & & & & \\
& ws & 3,36 & 0.05 & 0.43 \\
& & & & 0.81 \\
& ss & 3,36 & 0.15 & 0.41 \\
\hline
\end{tabular}


Table 3.4. Range of the number of antennations per replicate for the resident's response to intruder and intruder's response to resident of the same (TO-TO or PI-PI) colony or different (TO-PI, PI-TO) colonies, one-on-one interactions. $n=10$ per caste pairing, $\mathrm{ww}=$ worker-worker, $\mathrm{ws}=$ worker-soldier, $\mathrm{ss}=$ soldier-soldier.

\begin{tabular}{lllllllll}
\hline \multicolumn{4}{c}{ Resident response to Intruder } & \multicolumn{4}{l}{ Intruder response to Resident } \\
\hline & TO-TO & TO-PI & PI-PI & PI-TO & TO-TO & TO-PI & PI-PI & PI-TO \\
\hline ww & $2-35$ & $6-17$ & $4-21$ & $4-21$ & $4-21$ & $3-16$ & $5-17$ & $7-23$ \\
ws & $5-14$ & $3-14$ & $3-22$ & $3-12$ & $4-23$ & $3-12$ & $4-12$ & $5-19$ \\
ss & $5-13$ & $4-14$ & $3-30$ & $5-11$ & $3-12$ & $4-11$ & $5-25$ & $5-17$ \\
\hline
\end{tabular}




\section{Effects of Density:}

Overall there were few aggressive behaviors observed in five-on-one and five-on-five pairings across all Toronto-Pelee pairings. Aggressive responses were absent in workerworker nestmate and non-nestmate pairings (Table 3.5). For five-on-one worker-soldier assays aggressive encounters comprised $0.3-0.7 \%$ of all total interactions for nonnestmate pairings (resident-intruder and intruder-resident), and $0 \%$ for nestmate pairings (resident-resident). In soldier-soldier assays 5.0 - 6.3\% of responses were aggressive in non-nestmate pairings, with $0 \%$ aggression between nestmates (Table 3.5). In five-onfive worker-soldier pairings there was little difference in the number of aggressive responses between non-nestmates, $1.3-3.5 \%$ and nestmates, $2.2-3.9 \%$. In soldiersoldier pairings there were slightly more aggressive encounters in non-nestmate pairings, $1.3-8.2 \%$ compared to nestmate pairings, $0.4-1.7 \%$ (Table 3.5). Mean aggression scores were higher for nestmate and non-nestmate soldier-soldier pairings compared to worker-worker and worker-soldier pairings (Table 3.5). The most common aggressive responses were mandible flares. Lunge forward and biting was rare, but if observed occurred in soldier-soldier encounters. If a single individual exhibited a mandible flare, it was more likely to repeat this behavior in later encounters, regardless of whether the individual was a nestmate or non-nestmate.

There was no significant difference in mean antennation time for five-on-one workerworker pairings between nestmates (resident-resident) and non-nestmates (residentintruder) (Table 3.6). In worker-soldier and soldier-soldier pairings resident termites spent significantly longer antennating non-nestmate intruders compared to resident nestmates (Table 3.6, Figure 3.5). In five-on-five worker-worker and soldier-soldier pairings there were no differences in mean antennation time (s) between nestmates (resident-resident, intruder-intruder) and non-nestmates (resident-intruder, intruderresident) (Figure 3.6). In worker-soldier pairings antennation time was significantly longer for non-nestmate resident-intruder encounters compared to nestmate intruderintruder encounters (Table 3.6, Figure 3.6).

Comparing one-on-one, five-on-one and five-on-five density pairings there were no significant differences in antennation time for the residents' response to an intruder in 
both worker-soldier and soldier-solder castes (Table 3.7, Figure 3.7, Figure 3.8). There was a statistically significant difference in antennation time in worker-worker pairings, as resident workers spent longer antennating a single worker intruder in five-on-one pairings compared to resident workers antennating intruders in five-on-five encounters (Table 3.7, Figure 3.8). There were no significant differences in antennation time for the intruders' response to the resident across worker-worker, worker-soldier and soldier-soldier pairings (Table 3.7, Figure 3.8).

\section{Other behaviors observed}

Across all five-on-one and five-on-five caste pairings, oscillatory body movements and grooming behavior were frequently observed between non-nestmates. The number of oscillatory movements varied across trials from less frequent (0-3) to very frequent (2530 ), with very frequent oscillatory behaviors only between non-nestmate pairings. It was also noted that a single individual (either worker or soldier) was usually responsible for these frequent oscillatory movements, as this same individual would repeat this behavior in future encounters. Further, grooming behavior was common between non-nestmates. Such encounters could range from 5 - 40 seconds, and would begin with antennation of the other termite, followed by preening action with the mandible on the body and anus. Occasionally avoidance-like behaviors were observed between non-nestmate encounters. These behaviors included startle responses (rapid up-down movement of the body), moving backwards and rapidly turning in the opposite direction. 
Table 3.5. Percentage of aggressive responses and mean aggression score (MAS) over summed interactions for all five-on-one and five-on-five Toronto - Pelee pairings.

RI (resident-intruder), IR (intruder-resident), RR (resident-resident) and II (intruderintruder) are all tabulated from the same number of replicates (therefore total \# interactions is the same). $\mathrm{n}=10$ per caste pairing, $\mathrm{ww}=$ worker-worker, $\mathrm{ws}=$ workersoldier, ss = soldier-soldier, $\mathrm{NNM}=$ non-nestmate, $\mathrm{NM}=$ nestmate.

\begin{tabular}{cccccccccc}
\hline & ww & \multicolumn{3}{c}{ ws } & \multicolumn{3}{c}{ ss } \\
\hline 5-on-1 & $\begin{array}{c}\% \\
\text { aggr. }\end{array}$ & $\begin{array}{c}\text { Total } \\
\#\end{array}$ & MAS & $\begin{array}{c}\% \\
\text { aggr. }\end{array}$ & $\begin{array}{c}\text { Total } \\
\#\end{array}$ & MAS & $\begin{array}{c}\% \\
\text { aggr. }\end{array}$ & $\begin{array}{c}\text { Total } \\
\#\end{array}$ & MAS \\
\hline IR(NNM) & 0 & 245 & 1.00 & 0.7 & 230 & 1.01 & 6.3 & 159 & 1.07 \\
RI(NNM) & 0 & 245 & 1.00 & 0.3 & 230 & 1.00 & 5 & 159 & 1.06 \\
RR (NM) & 0 & 245 & 1.00 & 0 & 230 & 1.00 & 0 & 159 & 1.00 \\
\hline 5-on-5 & & & & & & & & & \\
\hline IR(NNM) & 0 & 235 & 1.00 & 1.3 & 230 & 1.02 & 8.2 & 232 & 1.09 \\
RI(NNM) & 0 & 235 & 1.00 & 3.5 & 230 & 1.04 & 1.3 & 232 & 1.19 \\
RR (NM) & 0 & 235 & 1.00 & 3.9 & 230 & 1.03 & 1.7 & 232 & 1.02 \\
II (NM) & 0 & 235 & 1.00 & 2.2 & 230 & 1.01 & 0.4 & 232 & 1.04 \\
\hline
\end{tabular}


Table 3.6. Summary of one-way independent ANOVA for differences in mean antennation time $(\mathrm{s})$ between nestmates (resident-resident, intruder-intruder) and nonnestmates (resident-intruder, intruder-resident) for all five-on-one and five-on-five Toronto - Pelee pairings. $\mathrm{n}=10$ per caste pairing (ww (worker-worker), ws (workersoldier) and ss (soldier-soldier)). Asterisks denote statistical significance $(P<0.05)$.

\begin{tabular}{ccccccc}
\hline & 5-on-1 & \multicolumn{5}{c}{ 5-on-5 } \\
Pairing & df & $\mathrm{F}$ & $\mathrm{p}$ & $\mathrm{df}$ & $\mathrm{F}$ & $\mathrm{p}$ \\
\hline \multirow{2}{*}{ Ww } & 1,18 & 0.02 & 0.88 & 3,36 & 0.43 & 0.74 \\
WS & 1,18 & 14.26 & $0.001^{*}$ & 3,36 & 0.077 & $0.05^{*}$ \\
SS & 1,18 & 5.26 & $0.03^{*}$ & 3,24 & 1.54 & 0.23 \\
\hline
\end{tabular}


a)

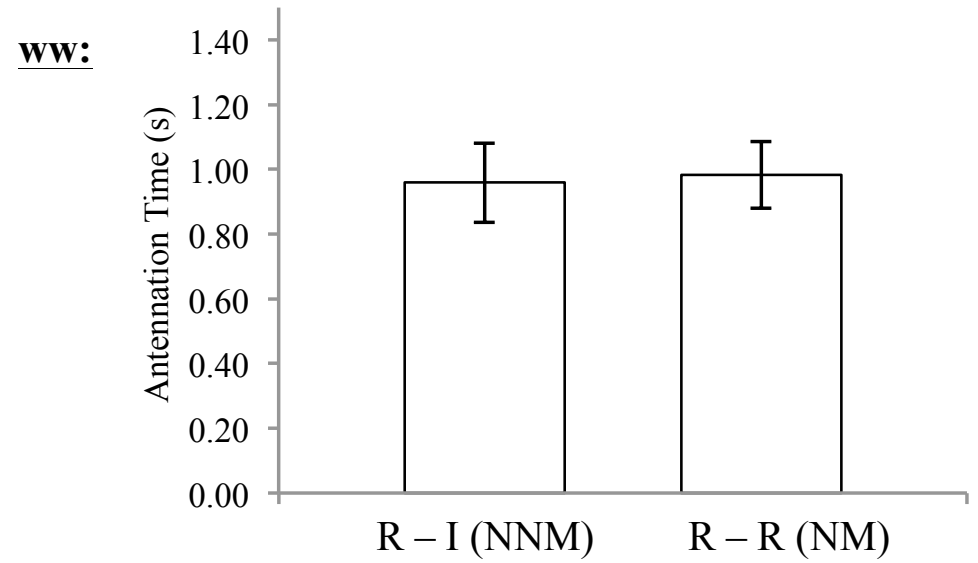

b)

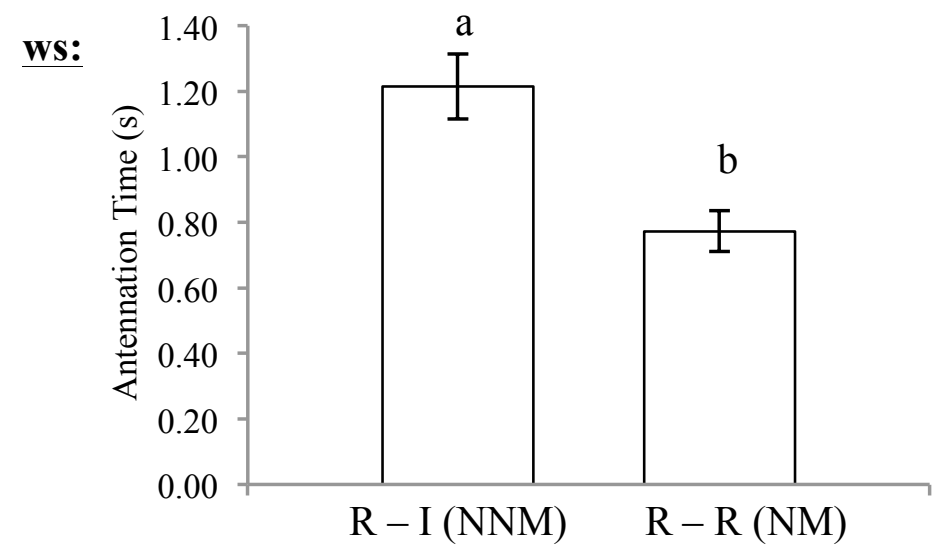

c)

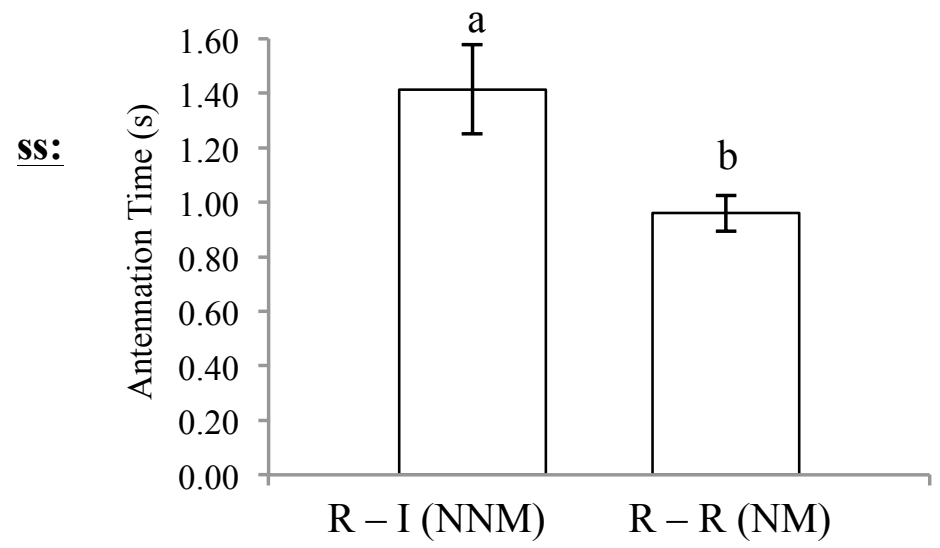

Figure 3.5. Mean antennation time ( $\pm \mathrm{SE}$ ) for a) worker - worker (ww), b) worker soldier (ws) and c) soldier-soldier (ss) five-on-one pairings. Resident-intruder (R - I) indicate mean scores for non-nestmate pairings (NNM, Toronto - Pelee Island), Resident-Resident (R-R) mean scores for nestmate pairings (NM, Toronto-Toronto or Pelee-Pelee). Letters in b) and c) denote statistical significance between groups ( $<<$ 0.01). $\mathrm{n}=10$ replicates per caste pairing (ww, ws, ss). 
a)

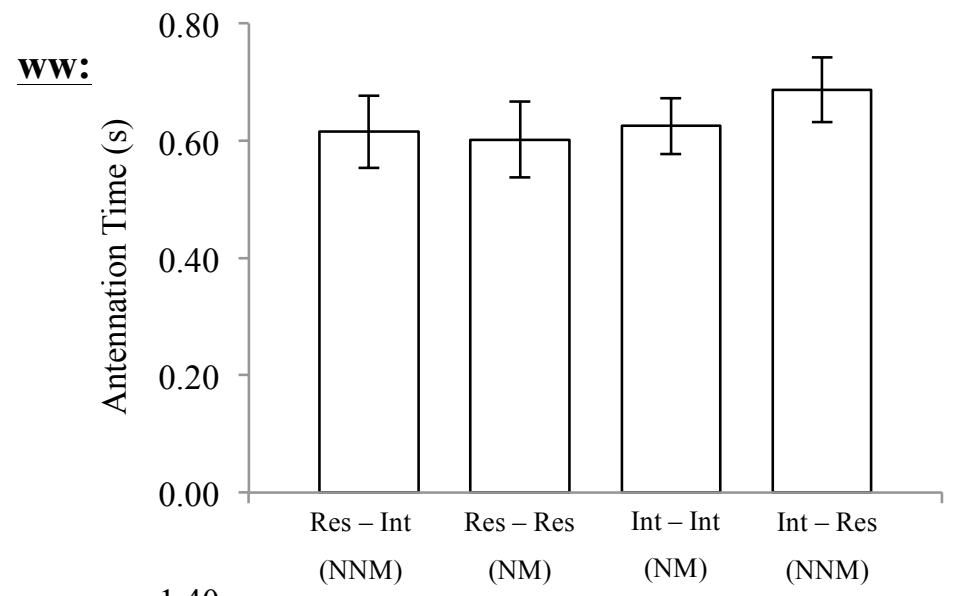

b)

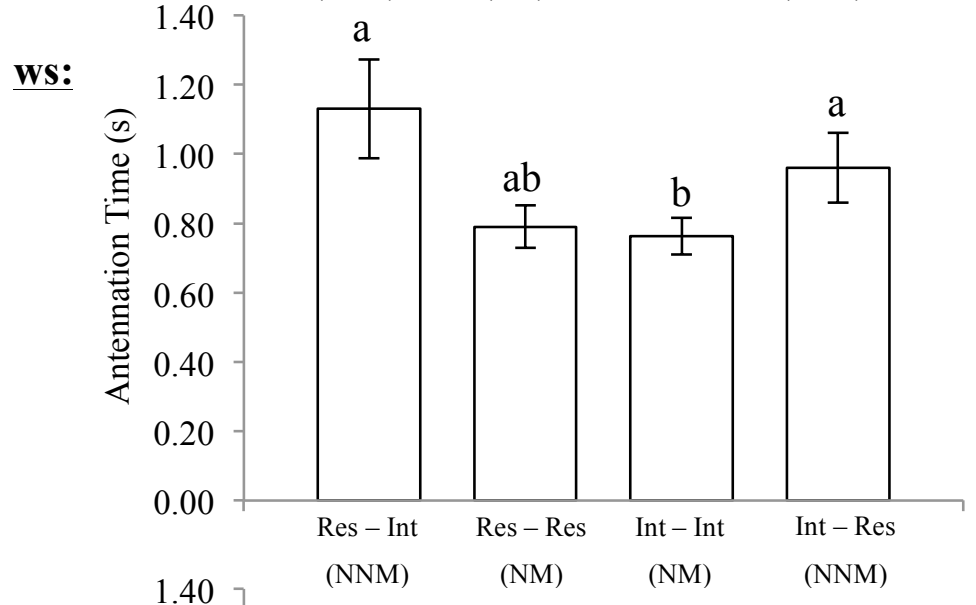

c)

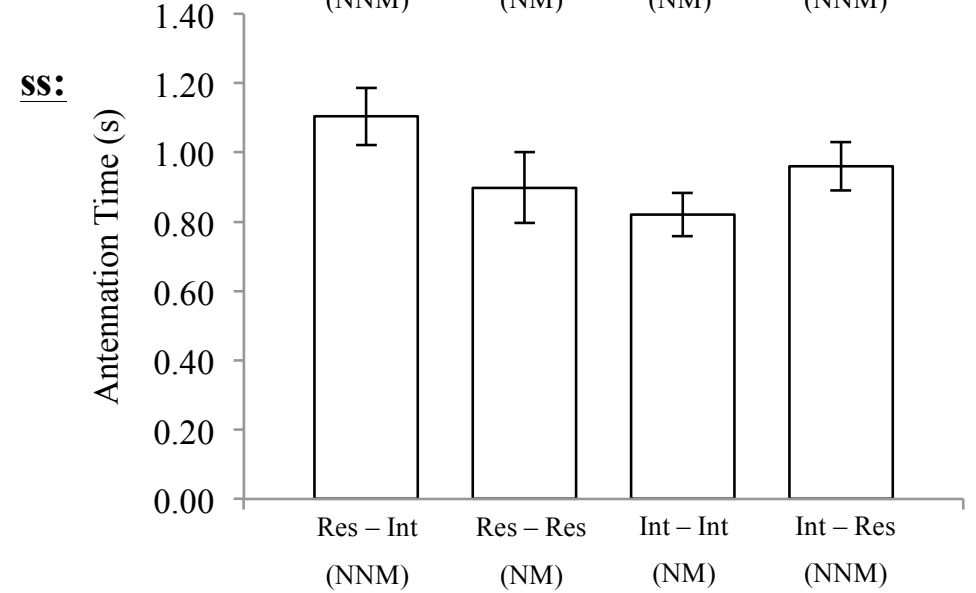

Figure 3.6. Mean antennation time ( $\pm \mathrm{SE}$ ) for a) worker - worker (ww), b) worker - soldier (ws) and c) soldier-soldier (ss) five-on-five pairings. Resident-intruder (R - I) and intruderresident $(\mathrm{I}-\mathrm{R})$ graphs indicate mean scores for non-nestmate pairings (NNM, TO - PI), Resident-Resident (R-R) and Intruder-Intruder (I-I) indicate mean scores for nestmate pairings (NM, TO-TO or PI-PI). Letters in $\mathrm{b})$ denote statistical significance between groups $(\mathrm{p}<0.05)$. $\mathrm{n}=$ 10 replicates per caste pairing (ww, ws, ss). 
Table 3.7. Effects of density on antennation time. Summary of one-way independent ANOVA for mean antennation time (s) of the resident response to an intruder and intruder response to resident comparing one-on-one, five-on-one and five-on-five density non-nestmate pairings. Scores compared for ww (worker-worker), ws (worker-soldier), ss (soldier-soldier) pairings. Asterisk denotes statistical significance. $\mathrm{n}=10$ per density pairing.

\begin{tabular}{lllllll}
\hline & \multicolumn{2}{l}{ Resident response to Intruder } & \multicolumn{4}{l}{ Intruder response to Resident } \\
\hline Pairing & $\mathrm{df}$ & $\mathrm{F}$ & $\mathrm{p}$ & $\mathrm{df}$ & $\mathrm{F}$ & $\mathrm{P}$ \\
\hline $\mathbf{w w}$ & 2,27 & 4.47 & $0.02^{*}$ & 2,27 & 0.22 & 0.80 \\
$\mathbf{w s}$ & 2,27 & 0.28 & 0.76 & 2,27 & 0.97 & 0.39 \\
ss & 2,18 & 0.96 & 0.40 & 2,18 & 3.07 & 0.07 \\
\hline
\end{tabular}


a)

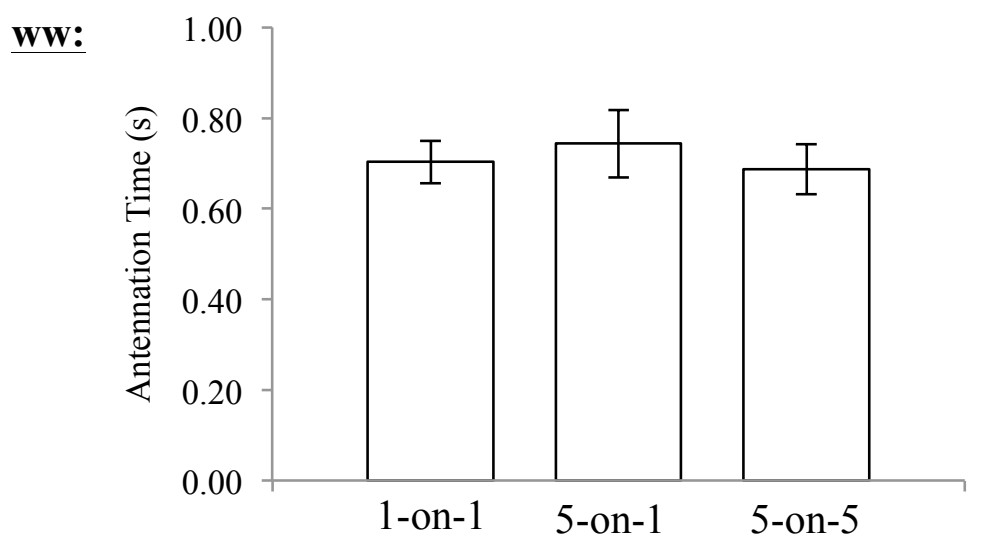

b)
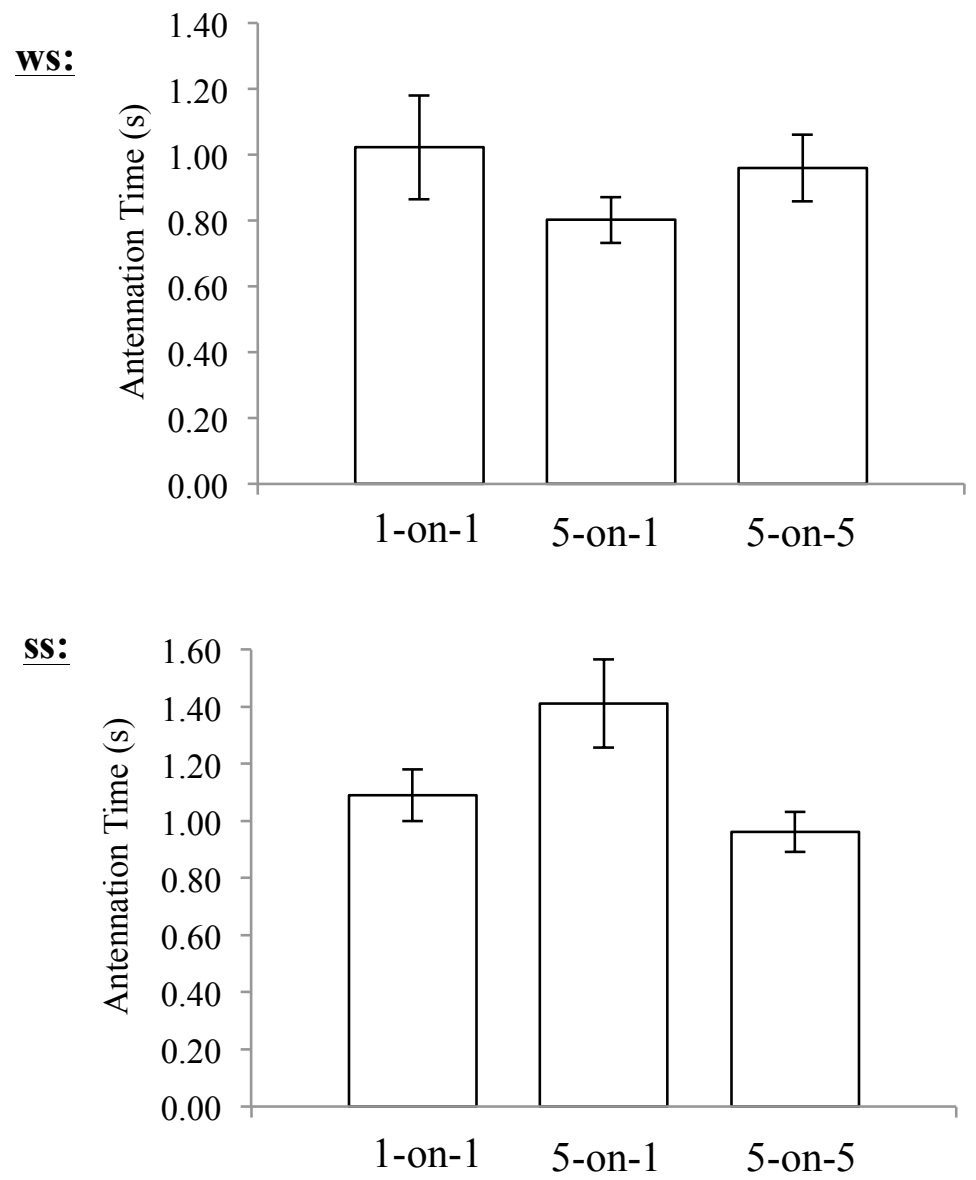

Figure 3.7. Mean antennation time (s) for one-on-one, five-on-one and five-on-five group pairings, intruder response to resident. Fig. 3.7 a) ww (worker-worker), b) ws (worker-soldier) and c) ss (soldier-soldier). 
a)

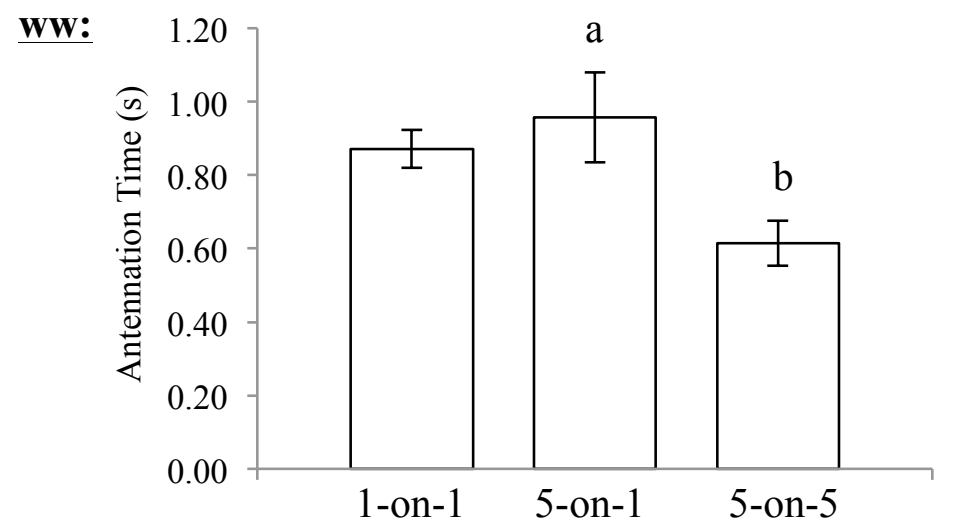

WS:

b)

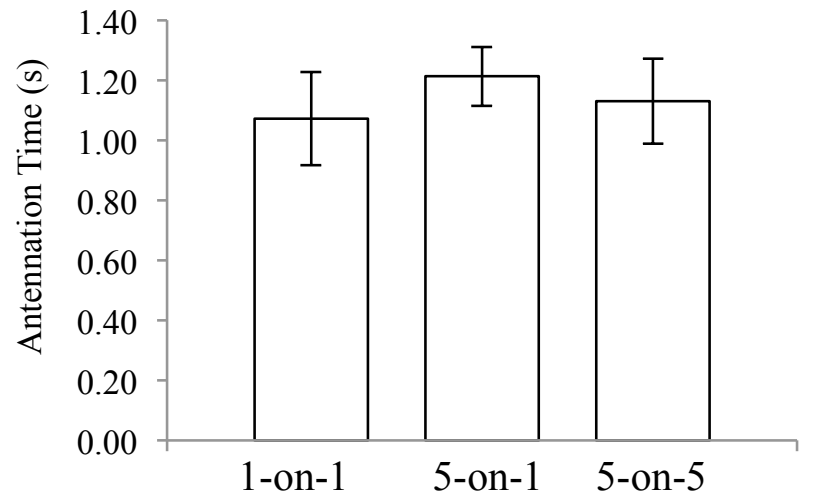

SS:

c)

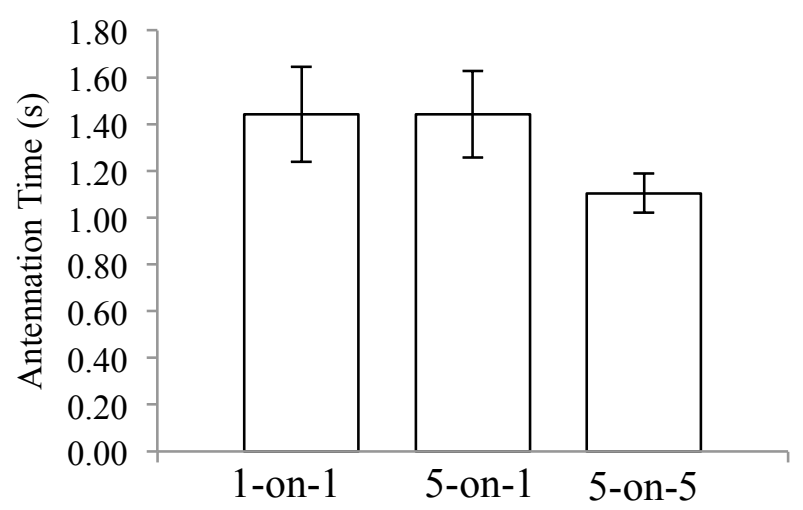

Figure 3.8. Mean antennation time (s) for one-on-one, five-on-one and five-on-five group pairings, resident response to intruder. Fig. 3.8 a) ww (worker-worker), b) ws (worker-soldier) and c) ss (soldier-soldier). Different letters denote statistical significance. 


\section{Soldier agitation and soldier crushing trials}

In soldier agitation trials there were more frequent aggressive responses and mean antennation scores were higher in agitated pairings compared to non-agitated soldiersoldier pairings (see Appendix B). Aggression scores were significantly higher in TO-TO agitated soldier pairings (MAS $=1.18 \pm 0.08$ ), with $17.7 \%$ total interactions being aggressive, compared to $5.9 \%$ of TO-TO non-agitated soldier pairings (MAS $=1.03 \pm$ $0.02),(F(3,35)=3.80, p<0.05)$. In agitated trials, if one soldier contacted any part of the other soldier, the contacted soldier would frequently react by a startle reaction (rapid jerking motion of the body), followed by rapidly turning around followed by a mandible flare or lunge flare, regardless of whether the termite was a nestmate or non-nestmate. If a soldier performed a mandible flare, it was likely to perform more as the trial progressed. Further, head-banging behavior (up-down movement of soldier head, which produced an audible clicking sound) was frequent in agitation trials, 33 of 287 interactions for non-nestmates, and 37 of 289 interactions for nestmates, and not observed in non-agitated trials. In soldier crushing trials, the most common behavior of the resident in response to the crushed soldier was either to antennate the crushed body or circle around the Petri dish without making contact. Mandible flares were uncommon and head banging absent.

\subsection{Resource Foraging Design}

\section{Termite Movement}

In assays involving nestmates, at the end of seven days the majority of workers were found in the central resource foraging site for both Pelee Island (Figure 3.9) and Toronto (Figure 3.10) pairings, but in all cases both stained and unstained workers were also observed in both left and right compartments. There was a roughly equal proportion of stained versus unstained individuals across compartments, although the number in each compartment varied between replicates (see Figure 3.9, Figure 3.10). For example, in the right container for TO-TO replicate \#3 and left container in TO-TO replicate \#4 fewer stained individuals appeared to leave their home environment (Figure 3.10). In nonnestmate pairings from the same population $\left(\mathrm{TO}_{\mathrm{A}}-\mathrm{TO}_{\mathrm{B}}\right.$ and $\left.\mathrm{PP}-\mathrm{PI}\right)$ a greater proportion of unstained workers remained in their home container after seven-days 
compared to nestmate pairings, although stained and unstained workers were still observed intermixing in left and right compartments (Figure 3.12).

A very different situation was observed when workers from different populations (TO - PI) were paired. A significantly greater proportion of workers remained in their home container rather than the central foraging resource and there was very little intermixing of stained and unstained individuals (Figure 3.11). In replicate \#1, all stained individuals remained in their original home compartment after seven-days, while all except one individual in the right compartment remained in the original home compartment $(\mathrm{n}=217)$, and replicates \#2-3 show similar trends (Figure 3.11). While stained and unstained individuals were found together in the central foraging resource, there was some separation noted, as in replicates \#1 and 2 one corrugated roll was observed to contain all stained workers, and the other roll all unstained workers. No overt aggression was ever observed in glass tubes or the middle resource.

Logistic regression confirmed that in non-nestmate pairings Toronto-Pelee individuals were $92 \%$ less likely to move (Odds ratio $0.08,95 \%$ CI $0.02,0.28$ ) compared to nestmate pairings Pelee - Pelee (Odds ratio 0.92, 95\% CI 0.40, 2.19) and Toronto - Toronto (Odds ratio $1.04,95 \%$ CI $0.51,2.13)$. There were no significant differences in movement between PI-PI and TO-TO nestmate pairings (Table 3.8).

In two-day assays, the majority of surviving individuals in nestmate pairings (TO-TO, PI-PI) would usually be found in one of the compartments (left, middle resource or right) (Table 3.9). Both stained and unstained individuals were intermixed, and although at times there was an equal proportion of stained to unstained individuals in a compartment the number of each found per compartment varied highly across replicates. Low survivorship in non-nestmate pairings (TO-PI) made observations difficult to interpret, however among the survivors there appeared to be less intermixing compared to nestmate pairings, as all surviving stained or unstained individuals would be found in separate compartments (Table 3.9). 

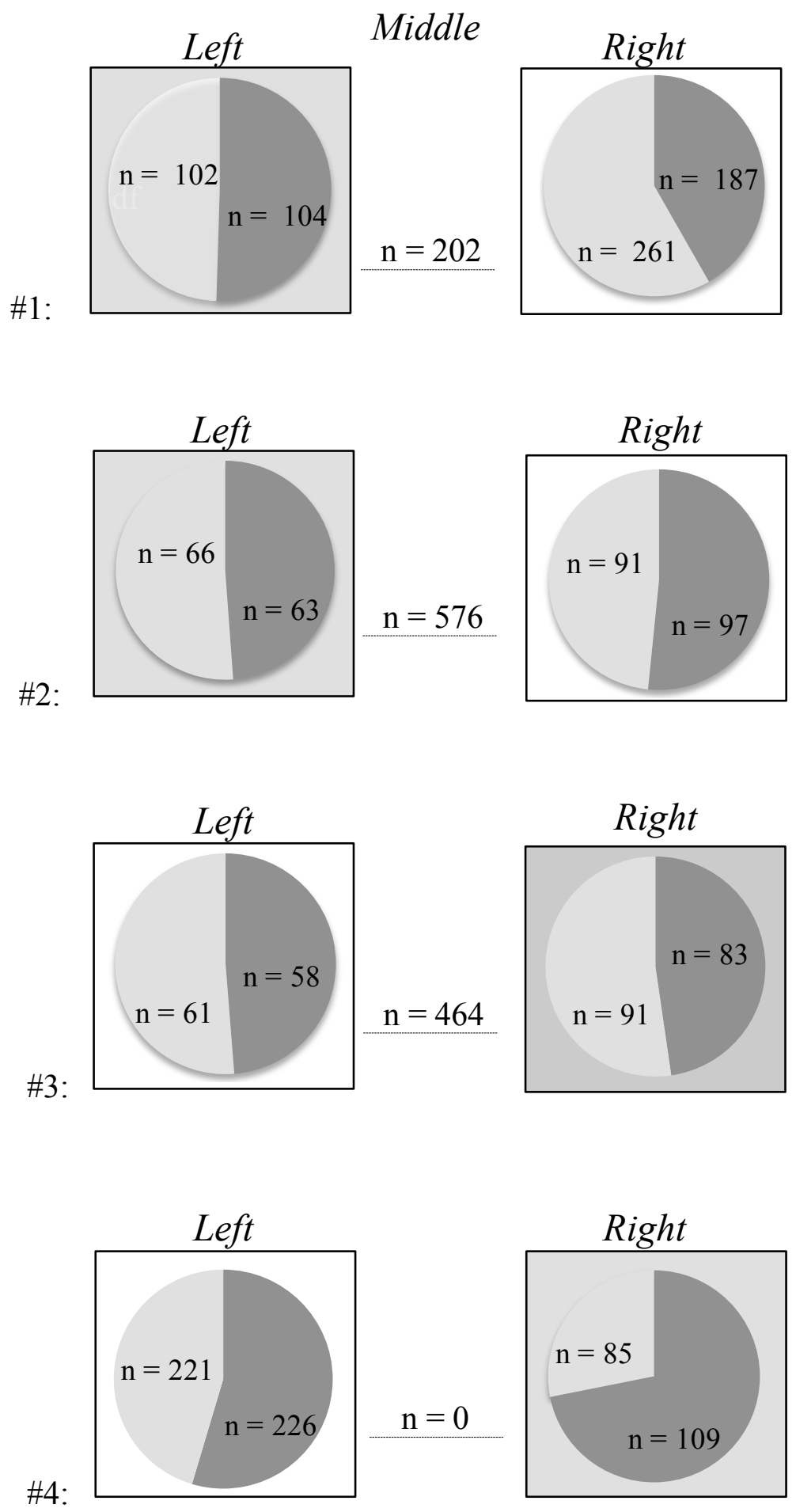

Figure 3.9. Seven-day resource design, Pelee Island - Pelee Island (nestmate) pairings, replicates \#1-4. Pie charts indicate the number of stained (gray) and unstained (white) survivors in left or right compartments, and total \# of survivors in middle compartment. Shade of background square indicates which side stained (gray) or unstained (white) individuals were placed at the start of the experiment. 

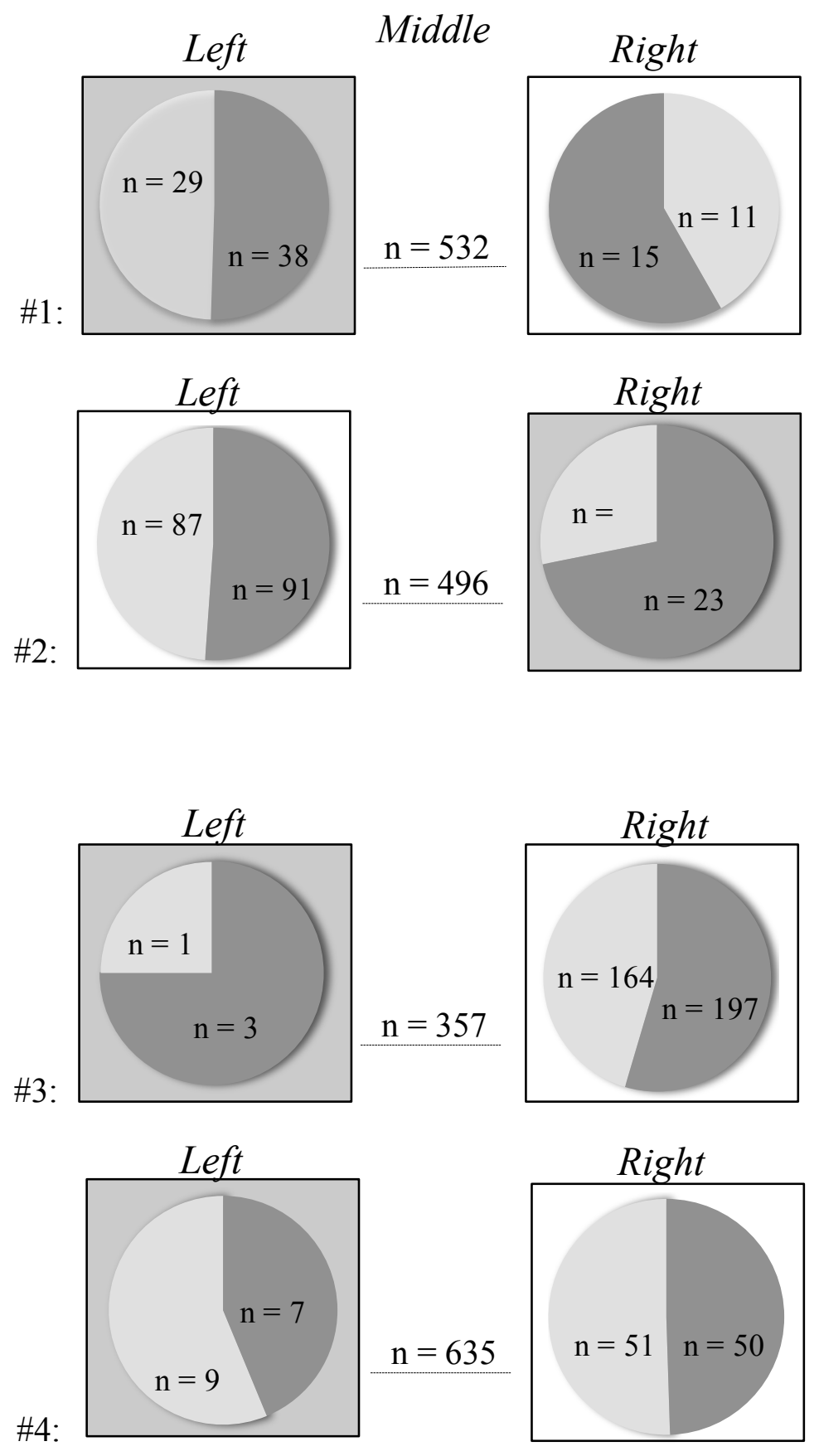

Figure 3.10. Seven-day resource design, Toronto - Toronto (TO-TO) (nestmate) pairings, replicates \#1-4. Pie charts indicate the number of stained (gray) and unstained (white) survivors in left or right compartments, and total \# of survivors in middle compartment. Shade of background square indicates which side stained (gray) or unstained (white) was placed at the start of the experiment. 


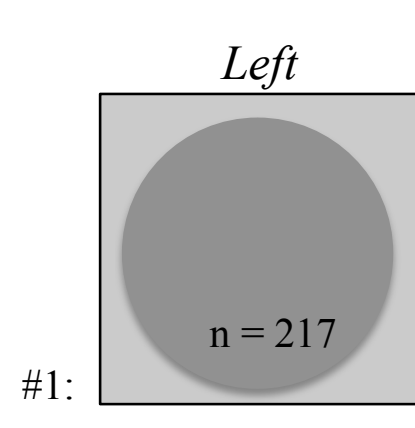

\section{Middle}
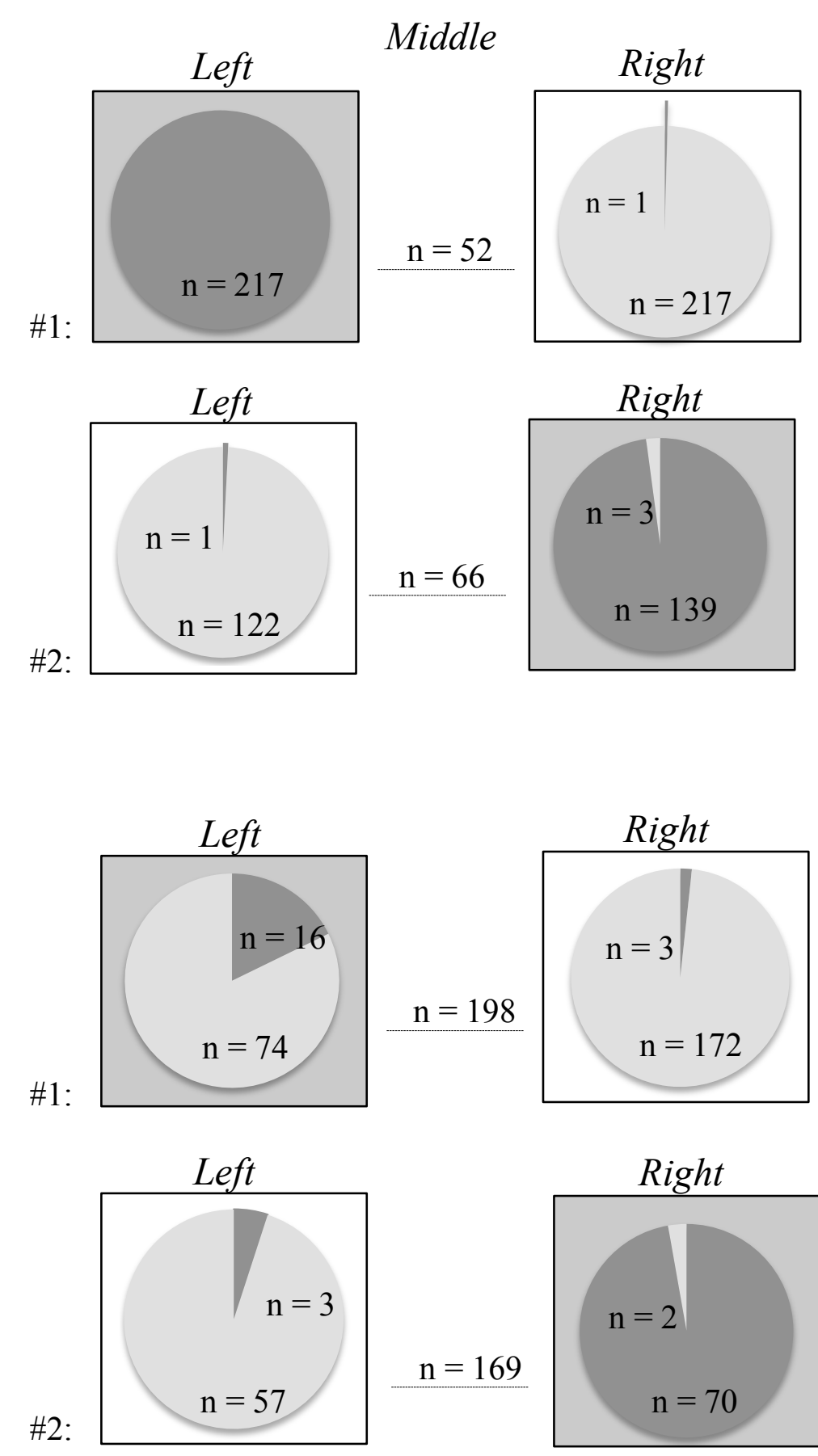

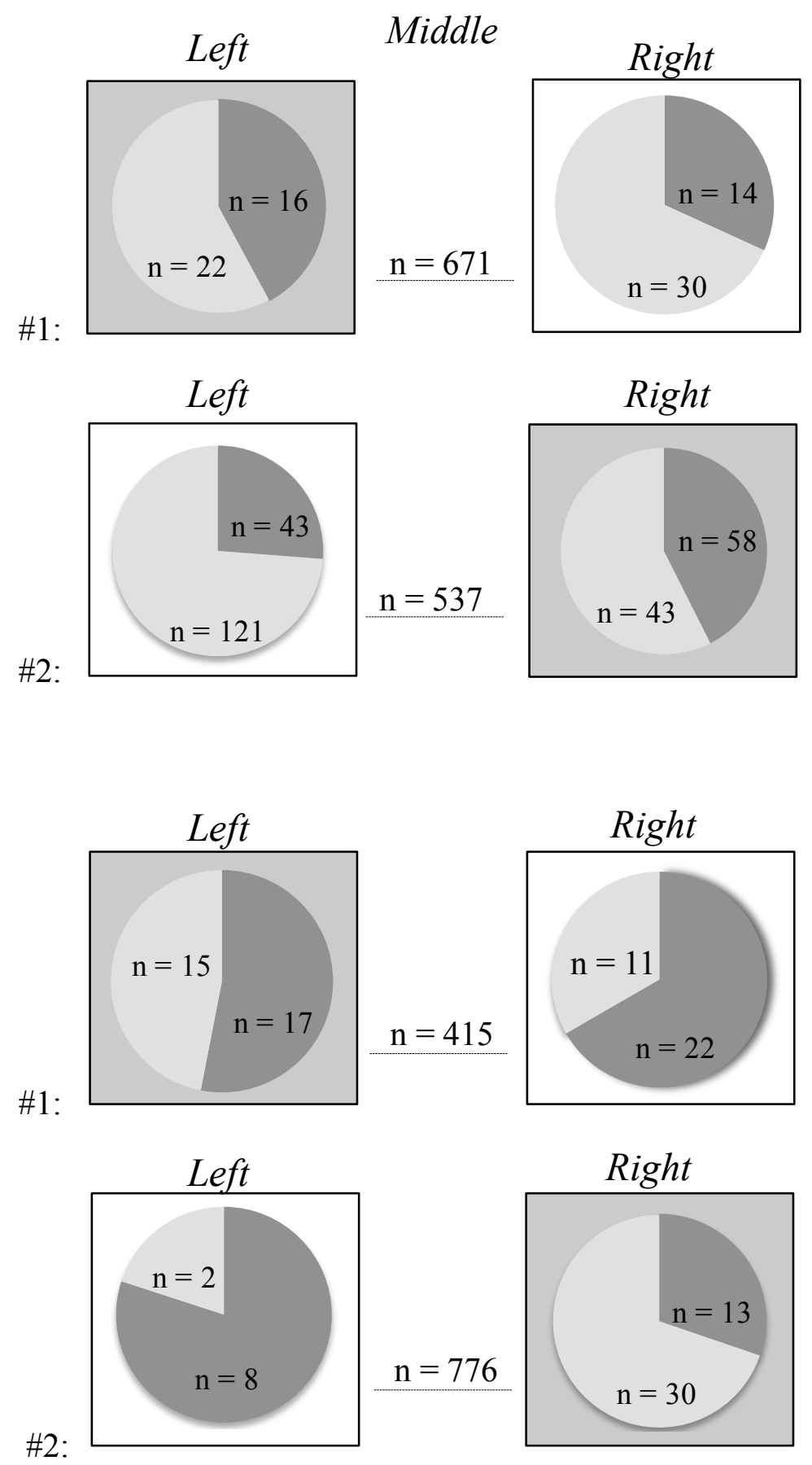

Figure 3.12. Seven-day resource design, Toronto locale $\mathrm{A}$ - Toronto locale $\mathrm{B}\left(\mathrm{TO}_{\mathrm{A}}-\mathrm{TO}_{\mathrm{B}}\right)$ (non-nestmate) pairings, replicates \#1-2 (top) and Point Pelee - Pelee Island (PP - PI) (nonnestmate) pairings, replicates \#1-2 (bottom). Pie charts indicate proportion and \% of stained (gray) and unstained (white) survivors in left or right compartments. Shade of background square indicates which side stained (gray) or unstained (white) was placed at the start of the experiment. 
Table 3.8. Summary of quasi binomial logistic regression comparing whether surviving $R$. flavipes workers moved from or stayed in their home container after seven days when paired with nestmates (TO-TO, PI-PI) or non-nestmates (TO-PI). $\mathrm{n}=12$ (4 per pairing). Constant value $=\mathrm{TO}-\mathrm{TO}$ pairing, dispersion parameter $=25.3$.

\begin{tabular}{llcccc}
\hline \multicolumn{5}{c}{ 95\% CI for odds ratio } \\
\hline & B (SE) & Lower & Odds ratio & Upper & p value \\
Constant & $0.04(0.36)$ & 0.51 & 1.04 & 2.13 & $>0.91$ \\
PIPI & $-0.09(0.43)$ & 0.40 & 0.92 & 2.12 & $<0.85$ \\
TOPI & $-2.50(0.67)$ & 0.02 & 0.08 & 0.28 & $<.001^{*}$ \\
\hline
\end{tabular}


Table 3.9. Two-day resource design, Toronto - Toronto (TO - TO), Pele Island - Pelee Island (nestmate) pairings, Toronto - Pelee Island (non-nestmate) pairings, replicates \#1-15. Total number of survivors in each compartment (left, middle, right) and total survivorship (15 stained, 15 unstained, /30).

\begin{tabular}{|c|c|c|c|c|}
\hline TO - TO & Left & Middle & Right & \# Survivors /30 \\
\hline 1 & 25 & 0 & 2 & 27 \\
\hline 2 & 3 & 10 & 14 & 27 \\
\hline 3 & 2 & 25 & 1 & 28 \\
\hline 4 & 21 & 1 & 2 & 23 \\
\hline 5 & 12 & 9 & 0 & 21 \\
\hline 6 & 5 & 19 & 0 & 24 \\
\hline 7 & 15 & 14 & 0 & 28 \\
\hline 8 & 2 & 1 & 26 & 29 \\
\hline 9 & 0 & 5 & 24 & 29 \\
\hline 10 & 21 & 4 & 4 & 29 \\
\hline 11 & 0 & 5 & 23 & 28 \\
\hline 12 & 25 & 0 & 1 & 26 \\
\hline 13 & 0 & 8 & 21 & 29 \\
\hline 14 & 0 & 6 & 24 & 30 \\
\hline 15 & 18 & 5 & 6 & 29 \\
\hline PI - PI & Left & Middle & Right & \# Survivors /30 \\
\hline 1 & 11 & 19 & 0 & 30 \\
\hline 2 & 0 & 1 & 25 & 26 \\
\hline 3 & 9 & 20 & 0 & 29 \\
\hline 4 & 3 & 9 & 13 & 25 \\
\hline 5 & 0 & 6 & 15 & 21 \\
\hline 6 & 2 & 0 & 26 & 28 \\
\hline 7 & 4 & 25 & 0 & 29 \\
\hline 8 & 0 & 5 & 22 & 27 \\
\hline 9 & 0 & 28 & 0 & 28 \\
\hline 10 & 30 & 0 & 0 & 30 \\
\hline 11 & 4 & 25 & 0 & 29 \\
\hline 12 & 23 & 2 & 0 & 25 \\
\hline 13 & 1 & 1 & 26 & 28 \\
\hline TO - PI & Left & Middle & Right & \# Survivors /30 \\
\hline 1 & 2 & 1 & 5 & 8 \\
\hline 2 & 2 & 4 & 0 & 6 \\
\hline 3 & 0 & 0 & 2 & 2 \\
\hline 4 & 0 & 12 & 2 & 12 \\
\hline 5 & 1 & 2 & 9 & 12 \\
\hline 6 & 0 & 0 & 1 & 1 \\
\hline 7 & 0 & 0 & 2 & 2 \\
\hline 8 & 1 & 0 & 13 & 14 \\
\hline 9 & 0 & 0 & 9 & 9 \\
\hline 10 & 0 & 0 & 2 & 2 \\
\hline 11 & 0 & 7 & 0 & 7 \\
\hline 12 & 10 & 0 & 6 & 16 \\
\hline 13 & 2 & 1 & 3 & 6 \\
\hline 14 & 8 & 3 & 0 & 11 \\
\hline 15 & 3 & 0 & 4 & 7 \\
\hline
\end{tabular}


a)

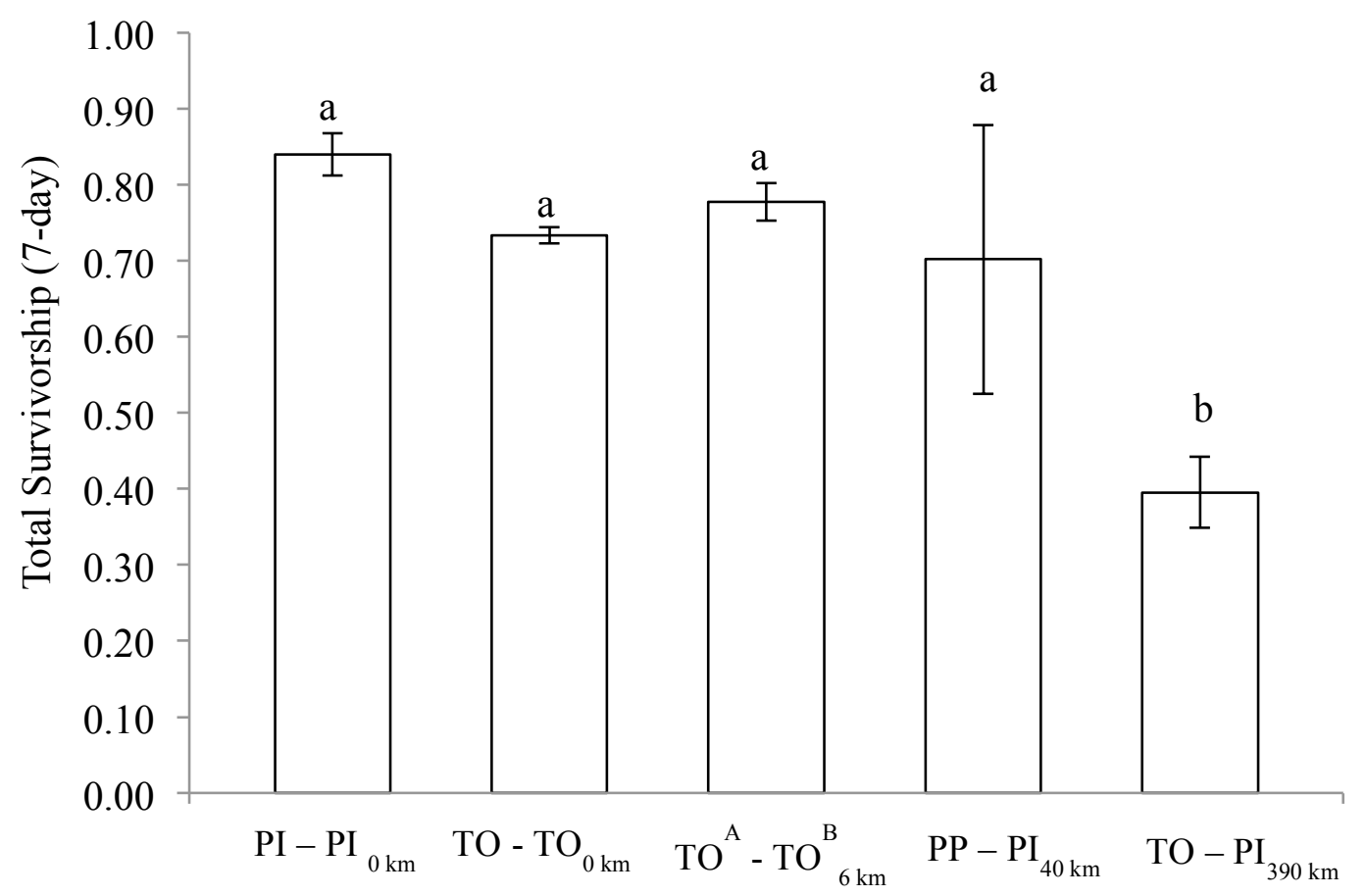

b)

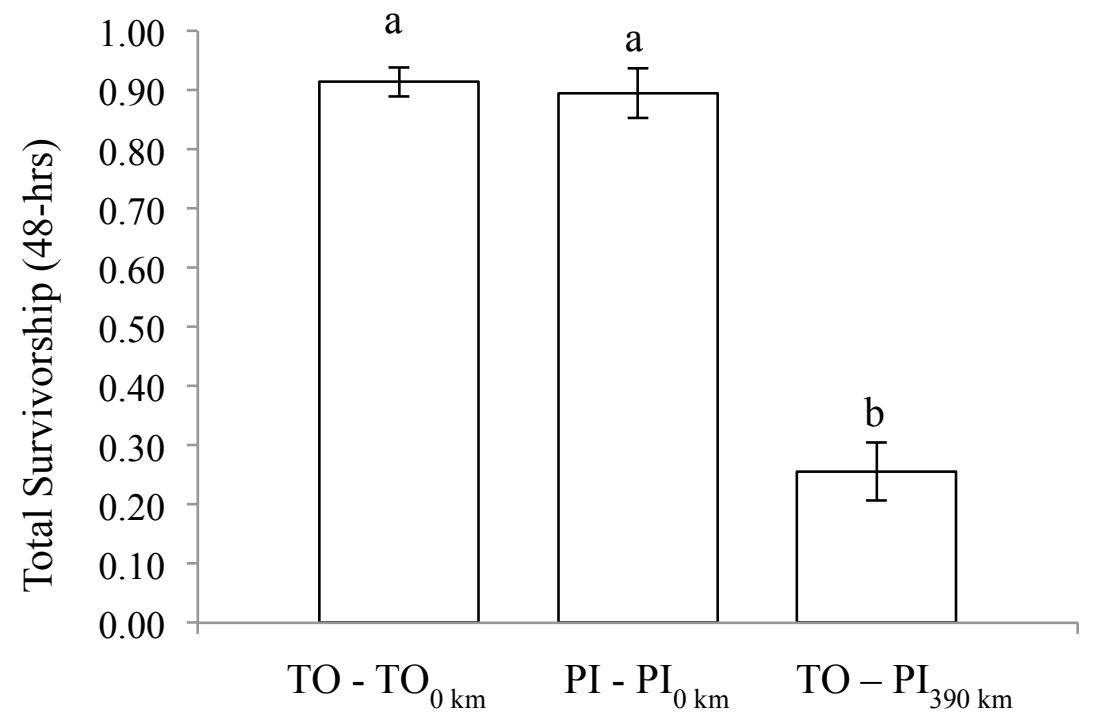

Figure 3.13. Mean total survivorship $( \pm S E)$ in a) seven-day resource design, and b) twoday resource design trials with combined survivorship of stained and unstained workers. Letters denote statistical significance between groups $(\mathrm{p}<0.001)$. 


\section{Survivorship}

The survival of workers varied significantly within and between nest pairings for both seven-day and two-day resource design assays. Survival was always $>70 \%$ in nestmate pairings (TO-TO, PI-PI) as well as non-nestmate pairings from within the same population $\left(\mathrm{TO}_{\mathrm{A}}-\mathrm{TO}_{\mathrm{B}}\right.$ and $\left.\mathrm{PP}-\mathrm{PI}\right)$ (Figure 3.13). In contrast worker survival was significantly lower in non-nestmate pairings (TO-PI), $(\mathrm{F}(4,11)=11.04, \mathrm{p}<0.001$; Figure 3.13, Table 3.10). In the seven-day trial the majority of dead individuals were not found, likely disintegrating into the substrate before they could be counted. The largest numbers of dead individuals were found in the TO-TO pairings $(n=143)$, followed by TO-PI $(\mathrm{n}=81)$ and PI-PI $(\mathrm{n}=28)$ pairings (Table 3.11). For TO-PI pairings dead individuals were observed under a microscope for signs of injury related to aggression, however bodies were too decomposed to detect noticeable signs (i.e. loss of limbs). In most TO-PI replicates a rotting smell was noted, particularly in the middle food resource. Within the food resource dead individuals were frequently found together on the moistened cardboard rolls. Survivorship was not associated with the use of Nile blue A cell stain, as there were no differences in survivorship between stained and unstained workers for both the seven-day and two-day resource foraging design (Figure 3.14). 
Table 3.10. One way ANOVA for differences in survivorship between stained versus unstained individuals, in Pelee Island - Pelee Island (PIPI), Toronto-Toronto (TO-TO) and Toronto - Pelee Island (TO-PI) pairings in seven-day and two-day resource design assays.

\begin{tabular}{lllll}
\hline & Pairing & df & F & p \\
\hline seven-day resource design & PIPI & 5,18 & 10.27 & 0.75 \\
& TOTO & 5,18 & 10.27 & 0.75 \\
& TOPI & 5,18 & 10.27 & 0.98 \\
two-day resource design & PIPI & 5,80 & 1.53 & 0.99 \\
& TOTO & 5,80 & 0.80 & 0.99 \\
& & & & \\
& TOPI & 5,80 & 0.84 & 0.71 \\
\hline
\end{tabular}


Table 3.11. Number of dead individuals found in the left, middle, right compartments or glass tubes for TO-TO, PI-PI and TO-PI pairings in the seven-day resource foraging design.

\begin{tabular}{llllll}
\hline Pairing & Left & Mid & Right & Tubes & TOTAL \\
\hline TOTO & 5 & 75 & 63 & 0 & 143 \\
PIPI & 11 & 2 & 15 & 0 & 28 \\
TOPI & 38 & 29 & 11 & 5 & 81 \\
\hline
\end{tabular}


a)

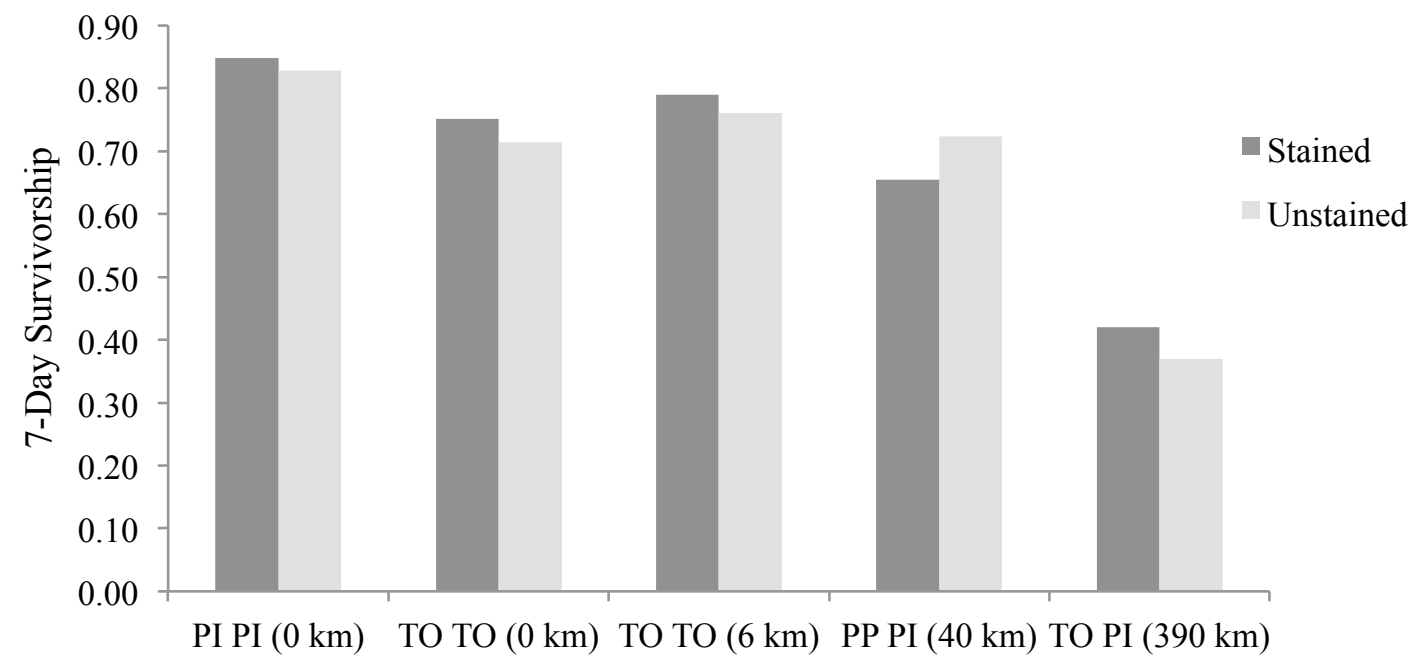

b)

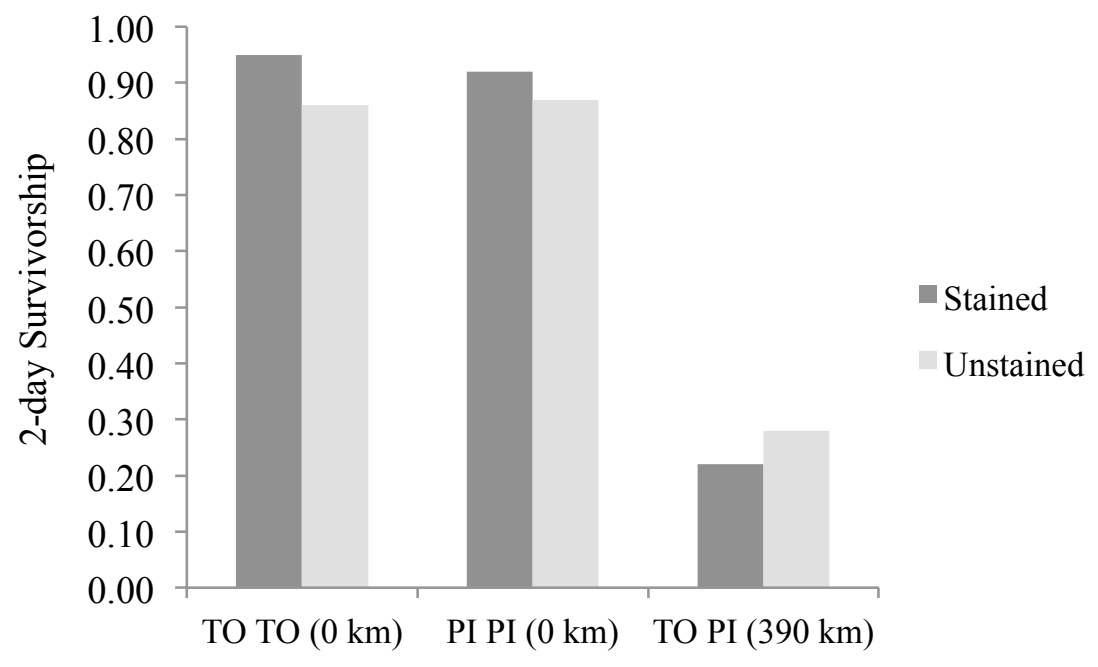

Figure 3.14. Mean survivorship in a) seven-day and b) two-day resource design assays between stained and unstained workers. 


\section{Chapter 4}

\section{Discussion}

\subsection{Aggression and nestmate discrimination in $R$. flavipes}

Results of the short-term Petri dish assays did not support the original hypothesis that the degree of intercolony aggression would increase with increasing geographic distance between colonies, as there was no evidence of elevated aggression when non-nestmates would interact compared to nestmates, regardless of caste or density. When observed aggressive responses, such as mandible flares and lunging forward at a conspecific were primarily expressed by the soldier caste. With a few exceptions there were also no significant differences in antennation between nestmates and non-nestmates across caste and density pairings, a behavior considered as a possible indicator of nestmate discrimination (Clément and Bagnères, 1998; Steiner et al., 2007; Huang et al., 2014;). The only significant differences were in five-on-one worker-soldier and soldier-soldier pairings where resident termites spent longer antennating non-nestmate intruders than resident nestmates. Aggressive behaviors and longer antennation by soldiers may relate to the fact that they are the first line of defense and engage in entrance guarding behaviors to prevent intruders from entering the nest. Further, in five-on-five worker-soldier pairings individuals spent less time antennating non-nestmates than in the five-on-one pairings. This would be expected, as individuals are likely to contact others more frequently with increasing group size in a Petri dish.

Thus, based on these findings one could conclude that $R$. flavipes lacks intercolony aggression and possibly nestmate discrimination, which would support previous work on this species (Grace, 1996; Polizzi and Forschler, 1998; 1999; Bulmer and Traniello, 2002; Fisher and Gold, 2003; Perdereau et al., 2011). All these studies were conducted using Petri dish assays that never lasted $>24$ hours. However, as noted by Breed (2003), a change in experimental design could lead to rather different results. This certainly would appear to be the case with both of the shared resource design experiments as there was a significant increase in worker mortality in inter-colony pairings compared intracolony pairings. The higher mortality occurred even in the two-day assays suggesting that 
mortality resulted from aggression, as death from factors such as disease and/or starvation should not have occurred in such a short timeframe. Unfortunately, the cadavers recovered were in such a state of decomposition it was not possible to see any evident signs of aggression.

One possible explanation is that only a small proportion of workers are actually aggressive (Polizzi and Forschler, 1998; 1999) and in assays involving higher densities there is a greater probability of such individuals being present. However, this seems somewhat unlikely, at least as a direct cause of the observed mortality. Over 200 workers were tested in the one-on-one, five-on-one and five-on-five assays and not a single individual exhibited high levels of aggression, so it seems unlikely that there would be enough aggressive individuals randomly selected for the foraging assays to generate the levels of mortality observed, especially in the two-day resource assays. As some soldiers had more aggressive responses than others, it is possible that there may be polyethism in the soldier caste. In Petri dish trials, an individual that expressed a specific behavior, such as an oscillatory body movement, grooming or mandible flare tended to do so on successive interactions. Further studies could address whether there are individual differences in behavioral responses within worker and soldier castes.

It is likely that $R$. flavipes requires specific contexts to display aggression (Polizzi and Forschler, 1998). As noted by Breed (2003), Zweden and d'Ettore (2010) and Chouvenc et al. (2011) one must take into account the natural ecological context when studying aggression and nestmate discrimination. For example, aggression in the Argentine ant, Linepithema humile occurred most frequently in assays involving competition for food or nest defense (Roulston, 2003). Similarly in the ground-nesting bee Lasioglossum zephyrum a plastic tube was used to resemble nest entrance holes in the field that are protected by guard bees. An intruder bee was then presented to guard bees blocking the entrance tube, and this context allowed for important insights into nestmate discrimination of a foraging bee species (Greenburg, 1979). Clearly the two-day and seven-day shared resource assays are closer to natural conditions than the short-term Petri dishes, as the resource-based assays allowed workers to burrow in substrate. Since subterranean termites are vulnerable to predation and desiccation they rarely expose themselves to the outside environment except during primary alate swarming or if the 
colony is infected by disease (Buczkowski and Bennett, 2008). In my resource assays, encountering non-nestmates while foraging for new resources may have elicited aggressive behavior. It is unknown whether aggressive interactions between nonnestmates occurred while feeding in the middle resource or when entering the other's home environment. If initial aggressive interactions between non-nestmates occurred when foraging for resources, survivors may have remained in their respective containers and thus would avoid individuals from the other colony.

Field studies indicate that foraging sites frequently overlap between both intra and interspecific colonies of Reticulitermes spp. in the field (Thorne et al., 1999; Deheer and Vargo, 2004; Deheer and Vargo, 2008; Perdereau et al., 2011). Given the potential cost of aggression one would expect the evolution of behaviors that minimize the possibility of negative encounters. While there was little evidence of aggression in the abovementioned studies, unpublished observations of $R$. flavipes suggest that worker-worker aggression may occur at points of contact while building and expanding foraging territory, and that soldiers block entrance tunnels to reduce such encounters (Forschler, pers. comm). Cornelius and Osbrink (2000) found that in resource-based assays R. flavipes and Coptotermes formosanus constructed separate foraging tunnels, suggesting a behavior that would result in fewer interactions and consequently costly aggressive interactions. The increased antennation of non-nestmates observed when soldiers were used in the Petri dish assays may be associated with entrance-guarding behavior that ensures only kin enter the nest territory.

Genetic analysis of multiple field colonies collected at the same foraging site suggest that extensive intermixing and intercolony breeding is likely avoided in field populations (Thorne et al., 1999; Bulmer and Traniello, 2002b). Differences in cuticular hydrocarbon profiles are one way that many social insect species differentiate kin from non-kin (Bagnères et al., 1991; Haverty et al., 1999; Kaib et al., 2004; Zweden and d'Ettore, 2010; Perdereau et al., 2010). The near absence of inter-colony mixing observed in the seven-day and two-day resource-sharing assays strongly suggests that $R$. flavipes is able to discriminate kin from non-kin. These results do not support the hypothesis that supercolony formation in Toronto populations' result from the inability to recognize kin from non-kin. In fact, as this population is genetically very similar as it arose from a 
single introduction (Scaduto et al., 2012) all individuals probably have very similar cuticular hydrocarbon profiles. The high level of intermixing observed in assays involving different colonies from Toronto $\left(\mathrm{TO}_{\mathrm{A}}-\mathrm{TO}_{\mathrm{B}}\right)$ and the presence of supercolonies in Toronto populations may be the result of the "dear enemy effect" (Breed, 2003; Fisher and Gold, 2003). In this situation neighboring colonies that are closely related avoid overt conflict, especially if resources are limited. Since colonies in Toronto are all descendants from one initial introduction their close genetic similarly may result in similar cuticular hydrocarbon profiles and thus they may avoid direct conflict with neighboring colonies (Scaduto et al., 2012). Lack of aggression between Toronto populations was also observed in Grace's (1996) seven-day resource design experiment.

Unfortunately, the fact that $R$. flavipes lives in underground tunnels makes it difficult to study behaviors under more realistic ecological conditions (Thorne et al., 1999; Deheer and Vargo, 2004) and in future studies the resource-foraging design could be modified so that movement and interactions of individuals could be videotaped over time. Some segregation of colonies was observed at the food resource, with stained and unstained non-nestmate workers found in different cardboard rolls, but it was not possible to determine if the two populations avoided foraging trail overlap or build passage blockages to prevent tunnel entry. Future studies on foraging interactions would benefit from using a planar arena, where individuals forage between stacked sheets of glass. This approach was effectively used to study the foraging interactions of $C$. formosanus. A design of this nature could be useful to provide insights to questions such as: Do foragers establish non-overlapping trails and block tunnels to avoid colony mixing? When and where do aggressive encounters normally occur, and which caste exhibits these aggressive behaviors? How might the addition of soldiers in different ratios effect worker movement? Does the caste ratio alter the levels and types of aggressive behavior? Do soldiers, the main line of defense, guard tunnel entrances? Cornelius and Osbrink (2000) found that when a greater proportion of $R$. flavipes and $C$. formosanus soldiers were added to a resource design experiment, fewer individuals shared the center food chamber. In addition, does aggression and intermixing follow a graded response as a function of geographic distance, with higher levels of intermixing between neighboring colonies than with more distant ones? Are there other non-aggressive behaviors that could be used as 
indicators of nestmate recognition? For example, measuring oscillatory body movements and grooming of non-nestmates, behaviours seen in some interactions may provide further insight. Furthermore, differences in antennation time may differ within a foraging gallery than in an open Petri dish.

The answers to these questions would certainly increase our understanding of the behavior of $R$. flavipes towards conspecifics. Research into these questions could also help clarify some of the apparent contradictions that exist in the current literature about the expression of aggression in this species. In previous literature it was not clear whether this species was able to detect kin from non-kin, but the results of this current study indicate that kin recognition remains intact in northern, introduced populations of $R$. flavipes. Based on the assumption that the presence of supercolonies arose due to a loss of kin recognition, it was proposed that 'switching on' kin recognition genes in supercolonies would lead to competition and consequently result smaller, more easily controlled colonies (Scaduto et al., 2012). However, the results of this study suggest that this approach is unrealistic, as supercolonies in Toronto have the ability to recognize kin. 


\section{References}

Bagnères, AG., Killian, A., Clément, JL., Lange, C. (1991) Interspecific recognition among termites of the genus Reticulitermes. J. Chem. Ecol. 12: 2397-2416.

Bernasconi, C., Maeder, A., Cherix, D., Pamilo, P. (2005) Diversity and genetic structure of the wood ant Formica lugubris in unmanaged forests. Ann. Zool. Fennici 42: 189-199.

Bordereau, C., Robert, A., Tuyen VV. (1997) Suicidal defensive behavior by frontal gland dehiscence in Globitermes sulphureus Haviland soldiers (Isoptera). Insectes Soc. 44: 289-296.

Bourke, AF. (2011) An expanded view of social evolution In: Principles of Social Evolution (ed Harvey PH), Oxford University Press, New York, USA, pp 16-17.

Breed, MD. (2003). Nestmate recognition assays as a tool for population and ecological studies in eusocial insects: a review. J. Kans. Entomol. Soc. 76: 539-550.

Breed, MD. (2014) Kin and nestmate recognition: the influence of W.D. Hamilton on 50 years of research. Anim. Behav. 92: 271-279.

Buczowski, G. and Bennett, G. (2008) Behavioral interactions between Aphaenogaster rudis (Hymenoptera: Formicidar) and Reticulitermes flavipes (Isoptera: Rhinotermitidae): the importance of physical barriers. J. Insect Behav. 21: 296-305.

Bulmer MS and Traniello JF. (2002a) Lack of aggression and spatial association of colony members in Reticulitermes flavipes. J. Insect. Behav. 15: 121-125.

Bulmer MS and Traniello JF. (2002b) Foraging range expansion and colony genetic organization in the subterranean termite Reticulitermes flavipes (Isoptera: Rhinotermitidae). Environ. Entomol. 31: 293-398.

Cherix, D. (1980) A preliminary note about structure, phenology and diet of a supercolony of Formica lugubris Zett. Insectes Soc. 27: 226-236.

Chouvenc, T., Bardunias, P., Hou-Feng, L., Elliott, ML., Su, NY. (2011) Planar arenas for use in laboratory bioassay studies of subterranean termites (Rhinotermitidae). Fla. Entomol. 94: 817-825.

Clément, JL. (1986) Open and closed societies in Reticulitermes (Isoptera:

Rhinotermitidae): geographic and seasonal variations. Sociobiology 11: 311-323.

Clément, JL. and Bagnères, AG. (1998) Nestmate recognition in termites. In Pheromone Communication in Social Insects: Ants, Wasps, Bees and Termites (Ed. Vander Meer, RK., Breed, MD., Espelie, KE., Winston, ML.). WestviewPress, USA, pp 126-155. 
Cornelius, ML. and Osbrink, WL. (2000) Interspecific interactions between Coptotermes formosanus and Reticulitermes flavipes (Isoptera: Rhinotermitidae) in laboratory assays. J. Insect Behav. 13: 757-770.

Crespi, BJ. (1994) Three conditions for the evolution of eusociality: Are they sufficient? Insectes Soc. 41: 395-400.

Deheer, CJ. and Vargo, EL. (2004) Colony genetic organization and colony fusion in the termite Reticulitermes flavipes as revealed by foraging patterns over time and space. Mol. Ecol 13: 431-441.

Deheer, CJ. and Vargo, EL. (2008) Strong mitochondrial DNA similarity but low relatedness at microsatellite loci among families within fused colonies of the termite Reticulitermes flavipes. Insectes Soc. 55: 190-199.

Dronnet, SM., Chapuisat, EL., Vargo, AG., Bagnères, Lohou, C. (2005) Genetic analysis of the breeding system of an invasive subterranean termite, Reticulitermes santonensis, in urban and natural habitats. Mol. Ecol. 14: 1311-1320.

Evans, TA., Forschler, BT., Grace, JK. (2013) Biology of invasive termites: a worldwide review. Annu. Rev. Entomol. 58: 455-474.

Fisher, ML. and Gold, RE. (2003) Intercolony aggression in Reticulitermes flavipes (Isoptera: Rhinotermitidae). Sociobiology 42: 651-661.

Giraud, T., Pederson, JS., Keller, L. (2002) Evolution of supercolonies: The Argentine ants of southern Europe. Proc. Natl. Acad. Sci. USA 99: 6075 - 6079.

Grace, JK., Cooper, PA. (1987) Association of the eastern subterranean termites, Reticulitermes flavipes (Kollar), with living trees in Canada. J. Entomol. Sci. 22: 353354.

Grace, JK., Abdallay, A., Farr, KR. (1989) Eastern subterranean termite (Isoptera: Rhinotermitidae) foraging territories and populations in Toronto. Can. Ent. 121: 551-556.

Grace, JK. (1990) Termites in eastern Canada: an updated review and bibliography. The International Research Group on Wood Preservation. Stockholm, Sweden doc. IRC/WP 14316 pp.

Grace, JK (1996). Absence of overt agonistic behavior in a nothern population of Reticulitermes flavipes (Isoptera: Rhinotermitidae). Sociobiology 28: 103-110. Greenburg, L. (1979) Genetic component of bee odor in kin recognition. Science 206: 1095-1097.

Hamilton, WD. (1972) Altruism and related phenomena, mainly in social insects. Ann. Rev. Ecol. Syst. 3: 193-232. 
Haverty, MI., Copren, KA., Getty, GM., Lewis, VR. (1999) Agonistic behavior and cuticular hydrocarbon phenotypes of colonies of Reticulitermes (Isoptera:

Rhinotermitidae) from Northen California. Ann. Entomol. Soc. Am. 92: 269-277.

Helantera H, Strassmann JE, Carrillo J, Queller DC. (2009) Unicolonial ants: where do they come from, what are they and where are they going? Trends Ecol. Evol. 24: 341349.

Holzer B, Chapuisat M, Kremer N, Finet C, Keller L. (2006) Unicoloniality, recognition and genetic differentiation in a native Formica ant. J. Evol. Biol. 19: 2031-2039.

Huang, Q., Guan, C., Shen, Q., Hu, C., Zhu, B. (2014) Aggressive behavior and the role of antennal sensillae in the termite Reticulitermes chinensis (Isoptera: Rhinotermitidae). Sociobiology 59: 1239-1251.

Husseneder, C., Simms, DM., Delatte, JR., Grace, KJ., Vargo, EL. (2012) Genetic diversity and colony breeding structure in native and introduced ranges of the Formosan subterranean termite, Coptotermes formosanus. Biol. Invasions. 14: 419-437.

Kaib, M., Jmhasly, P., Wilfert, L., et al. (2004) Cuticular hydrocarbons and aggression in the termite Macrotermes subhyalinus. J. Chem. Ecol. 30: 365-385.

Leniaud, L., Pichon, A., Uva, P., Bagnères, AG. (2009) Unicoloniality in Reticulitermes urbis: a novel feature in a potentially invasive termite species. Bull. Entomol. Res. 99: 110 .

Matsuura, K. and Nishida, T. (2001) Colony fusion in a termite: What makes the society “open”? Insectes Soc. 48: 378-383.

Matsuura, K. (2002) Colony-level stabilization of soldier head width for head-plug defense in the termite Reticulitermes speratus (Isoptera: Rhinotermitidae). Behav. Ecol. Siociobiol. 51: 172-179.

Myles, TG and Grace, JK. (1991) Behaviorial ecology of the eastern subterranean termite in Ontario as a basis for control. In Proceedings of the Ontario Ministry of the Environment Technology Transfer Conference, pp 547-554.

Olugbemi, BO. (2013) Intra- and inter-colonial agonistic behavior in the termite, Microcerotermes fuscotibialis Sjostedt (Isoptera: Termitidae: Termitinae). J. Insect Behav. 26: 69-78.

Oster GF and Wilson EO. (1978) Why is caste important? In: Caste and ecology in the social insects. Princeton University Press, Princeton, USA, pp 3-25.

Pearce, MJ., Cowie, RH., Pack, AS., Reavey, D. (1990) Intraspecific aggression, colony identity and foraging distance in Sudanese Microtermes spp. (Isoptera: Termitidae: Termitinae). Ecol. Entomol. 15: 71-77. 
Pederson JS., Krieger MJ., Vogel V., Giraud T., et al. (2006) Native supercolonies of unrelated individuals in the invasive Argentine ant. Evolution. 60: 782-791.

Perdereau, E., Dedeine, F., Christidès, JP., Dupont S., Bagnères, AG. (2011) Competition between invasive and indigenous species: an insular case study of subterranean termites. 13: $1457-1470$.

Perdereau, E., Dedeine, F., Christides, JP., Bagnères, AG. (2010) Variations in worker cuticular hydrocarbons and soldier isoprenoid defensive secretions within and among introduced and native populations of the subterranean termite, Reticulitermes flavipes. J. Chem. Ecol. 36: 1189-1198.

Preswitch, GD. (1984) Defense mechanisms of termites. Ann. Rev. Entomol. 29: 201232.

Polizzi, JM. and Forschler, BT. (1998) Intra- and interspecific agonism in Reticulitermes flavipes (Kollar) and R. virginicus (Banks) and effects of arena and group size in laboratory assays. Insectes Soc. 45: 43-49.

Pollizi, JM. and Forschler, BT. (1999) Factors that affect aggression among the worker caste of Reticulitermes spp. subterranean termites (Isoptera: Rhinotermitidae). J. Insect Behav. 12: 133-146.

Queller DC and Strassmann JF. (1998) Kin selection and social insects. BioSci. 48:165175.

R Core Team (2015). R: A language and environment for statistical computing. R Foundation for Statistical Computing, Vienna, Austria. URL https://www.R-project.org/.

Raffoul, M., Hecnar, SJ., Prezioso, S., Hecnar, DR., Thompson, GT. (2011) Trap response and genetic structure of eastern subterranean termites (Isoptera: Rhinotermitidae) in Point Pelee National Park, Ontario, Canada. Can. Entomol. 143: $263-271$.

Roulston, TH., Buczowski, G. Silverman, J. (2003) Nestmate discrimination in ants: effect of bioassay on aggressive behavior. Insectes Soc. 50: 151-159.

Rubenstein, DI. (1978) On predation, competition and the advantages of group living In: Perspectives in Ethology, pp 205-231.

Scaduto, DA., Garner, SR., Leach, EL., Thompson, GJ. (2012) Genetic evidence for multiple invasions of the eastern subterranean termite into Canada. Environ. Entomol. 41:1680-1686.

Shelton, TG and Grace, JK. (1996) Review of agonistic behaviors in the Isoptera. Sociobiology 28: $155-176$. 
Šobotník, J., Jirošová, A., Hanus, R. (2010) Chemical warfare in termites. J. Insect Physiol. 56: 1012-1021.

Šobotník, J., Bourguignon, T., Hanus, R., Demianova, Z. et al. (2012) Explosive backpacks in old termite workers. Science 337: 436.

Steiner, FM., Schlick-Steiner BC., Moder K, Stauffer C et al. (2007) Abandoning aggression but maintaining self-nonself discrimination as a first stage in ant supercolony formation. Curr. Biol., 17: 1903-1907.

Su, NY., Ban, PM. Scheffrahn, RH. (1991) Evaluation of twelve dye markers for population studies of the eastern and formosan subterranean termite (Isoptera: Rhinotermitidae) Sociobiology 19: 349-362.

Thorne BL. (1997) Evolution of eusociality in termites. Annu. Rev. Ecol. Syst. 28: 27-54.

Thorne BL, Traniello, JF, Adams ES, Bulmer MS. (1999) Reproductive dynamics and colony structure of subterranean termites of the genus Reticulitermes (Isoptera Rhinotermitidae): a review of the evidence from behavioral, ecological, and genetic studies. Ethol. Ecol. Evol. 11: 149-169.

Tsutsui, ND., Suarez, AV., Holway, DA., Case, TJ. (2000) Reduced genetic variation and the success of an invasive species. Proc. Natl. Acad. Sci. USA. 97: 5948-5953.

Uchima, SY., Grace, KJ. (2009) Interspecific agonism and foraging competition between Coptotermes formosanus and Coptotermes gestroi (Blattodea: Rhinotermitidae). J. Chem. Ecol. 30: 365-385.

Vargo, EL., Husseneder, C., Woodson, D., Waldvogel, MG., et al. (2006) Genetic analysis of colony and population structure of three introduced populations of the Formosan subterranean termite (Isoptera: Rhinotermitidae) in the continental United States. Environ. Entomol. 35: 151-166.

Vargo, EL. and Husseneder, C. (2011) Genetic structure of termite colonies and populations. Pages 321 - 347 In Biology of Termites: A Modern Synthesis (Ed. Roisen, Y.). Springer Netherlands.

Vargo, EL. (2003) Genetic Structure of Reticulitermes flavipes and R. virginicus (Isoptera: Rhinotermitidae) colonies in an urban habitat and tracking of colonies following treatment with hexaflumuron bait. Environ. Entomol. 32: 1271-1282.

Wilson, EO. (1971) The insect societies. Harvard University Press, Cambridge, USA. 548 pgs.

Zweden, JS. and d'Ettorre P. (2010) Nestmate recognition in social insects and the role of Hydrocarbons. Pages 222- 243 In Insect Hydrocarbons: Biology, Biochemistry, and Chemical Ecology (Ed. Blomquist, GJ. \& Bagnères, AG.). Cambridge University Press, UK. 
Appendices

a)

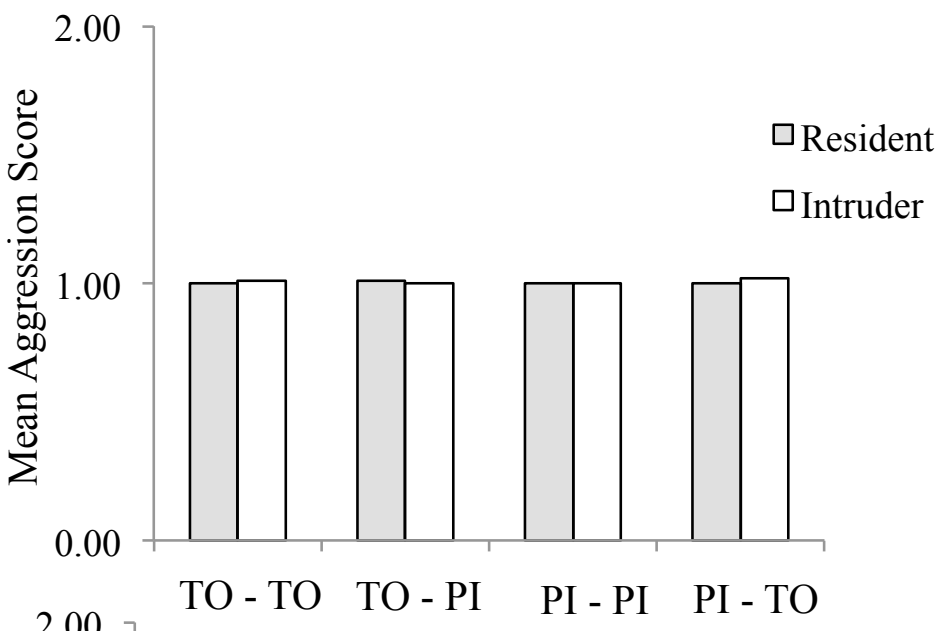

b)
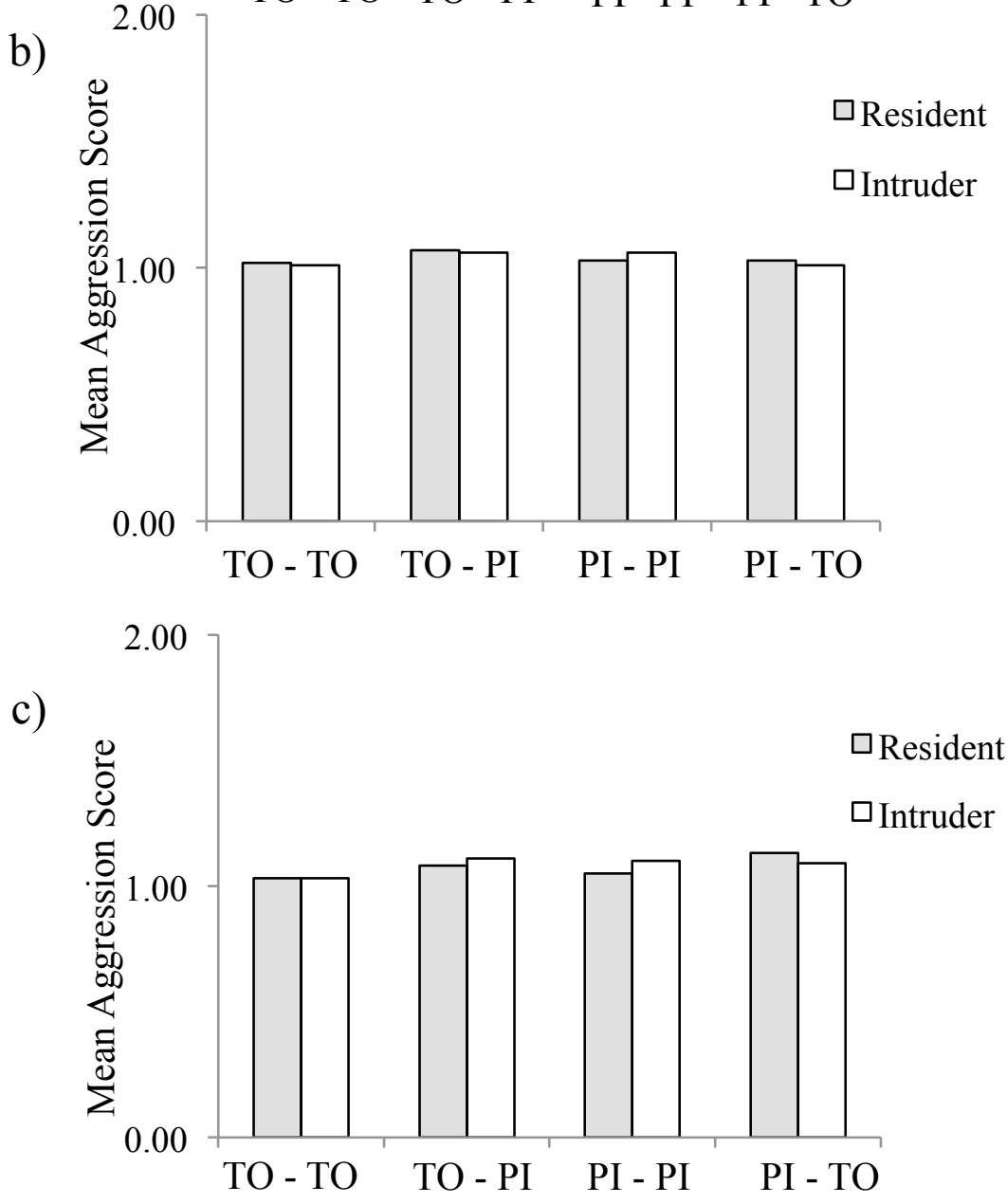

Appendix A: Mean aggression score for 1-on-1 a) worker-worker, b) worker-soldier, and c) soldier-soldier pairings between nestmates (TO - TO, PI - PI) and non-nestmates (TO - PI, PI - TO). 


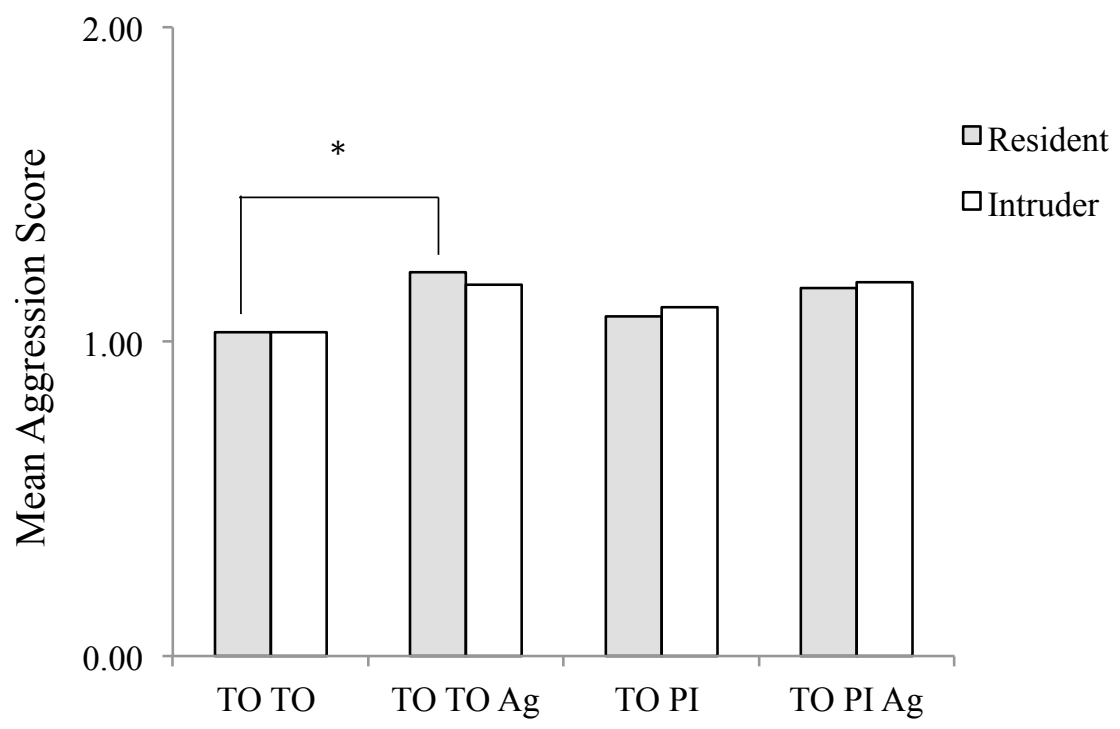

Appendix B: Mean aggression score for 1-on-1 soldier-soldier non-agitated nestmate pairings (TO TO = Toronto-Toronto), agitated nestmate pairings (TO TO Ag = TorontoToronto), non-agitated non-nestmate pairings (TO PI = Toronto-Pelee Island), agitated non-nestmate pairings (TO PI = Toronto-Pelee Island). Asterisk denotes statistical significance using Tukey's poc hoc test $(\mathrm{p}<0.05)$. 


\title{
Curriculum Vitae
}

\author{
Name: \\ Victoria Simkovic \\ Post-secondary \\ University of Toronto at Mississauga \\ Education and \\ Mississauga, Ontario, Canada \\ Degrees: \\ 2003-2007 HBSc. \\ The University of Western Ontario \\ London, Ontario, Canada \\ 2014-2016 M.Sc. \\ Honours and
Awards: \\ Related Work \\ Experience \\ President's Prize for Best Poster at the \\ Entomological Society of Canada conference \\ in Montreal, Quebec (2015). \\ Teaching Assistant \\ The University of Western Ontario \\ 2014-2016
}

\section{Conference Posters and Presentations:}

Simkovic VS. 2016. Kin-sorting maintains social order in populations of the eastern subterranean termite (Reticulitermes flavipes) (presentation). Ontario Ecology, Ethology and Evolution Colloquium, University of Toronto, Ontario.

Simkovic VS. 2015. Kin-sorting maintains social order in populations of the eastern subterranean termite (Reticulitermes flavipes) (poster). Joint Annual Meeting of the Entomological Society of Canada, Montreal, Quebec. 
